\title{
Income Inequality During China's Economic Transition
}

\author{
Dwayne Benjamin \\ Loren Brandt \\ John Giles \\ Sangui Wang
}

July 2005

Prepared for the forthcoming volume, China's Economic Transition: Origins, Mechanisms, and Consequences, edited by Loren Brandt and Thomas Rawski. We thank conference participants at the two preliminary conferences, especially the Second conference in Pittsburgh, November 2004, and our discussant, Jere Behrman, for their comments. We appreciate the financial support of the Poverty and Economic Policy (PEP) Research Network. Benjamin and Brandt thank the Social Sciences and Humanities Research Council of Canada, and Giles the National Science Foundation, SES-0214702, for additional financial support of this research. 


\begin{abstract}
This paper provides an overview of the evolution of income inequality in China from 1987 to 2002, employing three series of data sets. Our focus is on both urban and rural inequality, as well as the urbanrural gap, with the objective of summarizing several "first-order" empirical patterns concerning the trajectory of inequality through the reform period. We document significant increases of inequality within China's urban and rural populations. In rural areas, increased inequality is primarily related to the disequalizing role of non-agricultural self-employment income and slow growth in agricultural income from the mid-1990s onward. Poverty persists, and tied in part to slow growth in agricultural commodity prices. In urban areas, the declining role of subsidies and entitlements, the increase in wage inequality and the layoffs during restructuring, have fueled the growth in inequality within urban areas. Poverty levels, however, are very low. We find that spatial (regional) dimensions of inequality are significant, but are much less important than commonly believed for both the urban and rural populations, and for differences between urban and rural areas. Accounting for urban-rural reclassification, which otherwise exaggerates the rising urban-rural gap, we find a relatively stable ratio of urban to rural incomes. This hides some geographical variation, however: The urban-rural gap is increasing more rapidly in interior provinces, where SOE's had a more dominant role in economic activity in urban areas, than in coastal provinces where the non-state sector was more important earlier in the reform period.
\end{abstract}




\subsection{Introduction}

The primary motivation for China's economic reforms was to increase economic growth, and raise living standards after nearly twenty years of stagnation. Given the move to more market-based income determination, the reforms had the potential to conflict with inherited egalitarian-motivated socialist institutions and rhetoric. To what extent have the reforms led to widening inequality? Who have been the winners and losers? Have the reductions in poverty that accompanied growth been sufficient to alleviate concerns over inequality? Do increases in inequality threaten the long-run sustainability of the reforms? Are there identifiable patterns in the evolution of the income distribution that suggest potential policy responses?

The objective of this chapter is to document the evolution of inequality, and the income distribution more generally, during the reform period, and where possible to draw conclusions concerning the role that transition has played in increasing inequality. The centerpiece of our paper is the assembly of three series of cross-section data sets that allow a relatively consistent calculation of inequality from the mid-1980s onwards. It turns out that establishing "first-order" facts about Chinese inequality is quite difficult, and that unfortunately, conclusions hinge on mundane (but important) issues of measurement and data quality. In this regard, we are handicapped by the fact that much of the household level survey data collected annually by China's National Bureau of Statistics are not in the public domain.

Several of our conclusions line up with the existing literature on inequality in China. First, overall inequality has unambiguously risen in China, even since 1987, the first year for which we have data and several years after the reforms began. This inequality has increased in both urban and rural China, though as far as we can tell, the increase is higher in urban China. But, most of our evidence also suggests that the "official” estimates of inequality are probably too low, with the true Gini probably in the 0.40 to 0.50 range for both urban and rural areas. The overall (combined urban-rural) Gini probably exceeds 0.50, which is comparable to levels observed in South America.

Second, in urban China, absolute living standards have risen so much that even with rising inequality, most of the poverty (or "low income," more accurately) has been eliminated, at least if someone uses a "reasonable" benchmark. In rural China, significant gains in income growth during the late 1970s and early 1980s resulting from the introduction of HRS pulled tens of millions out of poverty. Further reductions occurred through the early-to-mid 1990s, but there was deterioration the last half of the 1990s, that may have reversed in only the last year or two. There remain reasons for concern, at least as far as our data show: for a significant number of households, incomes have remained flat or fallen for a decade or more, and the very poor may be worse off.

In a number of key respects, however, our findings are at odds with some of the conventional wisdom. Overall, geography, as captured by the province or village/city one lives in, plays a much less 
important role than one might expect: at least half, and perhaps as much as two-thirds, of estimated inequality is driven by income differences between "neighbors" as opposed to income differences based on location (city or village). The role of provincial differences is even smaller.

The same is true for urban-rural differences. Although urban incomes may be on average twothirds to three-quarters higher than rural incomes, these differences are the source of a relatively small proportion of overall inequality in China. More generally, great care must be taken when interpreting "urban-rural” income gaps, especially using official (NBS) data: the accelerating reclassification of rural areas as urban tends to exaggerate rural-urban income differences, as fast growing rural areas are relabeled as urban. Moreover, significant differences in the cost of living between urban and rural dampen the raw income differentials.

There does, however, appear to be significant differences in the inequality (and income growth) dynamics between interior and coastal provinces. Inequality increased more rapidly in the interior provinces, a product of a more rapid increase in rural income inequality, and a widening urban-rural income differential. As suggested by related research on growth and structural transformation by Brandt, Hsieh and Zhu (2005), some of this can be linked to the more significant legacy of the state sector in the interior provinces and urban bias. In the more dynamic coastal provinces, more rapid job growth in the non-state sector helped reduce urban-rural differentials by fostering more rapid rural income growth, and simultaneously helped to keep increases in rural inequality down.

Our findings regarding the role of geography and urban-rural differences suggest that we need to focus more attention on the institutions influencing the distribution of endowments, including both human and physical capital, the allocation of factors of production, and factor returns. In the countryside, most of the level and growth of inequality is due to unequal access to non-farm family business income. In the cities, the decline in subsidies and unequal wage incomes are playing an increasing role in raising inequality. Increasing returns to higher education are very important in explaining growing dispersion of wage earnings. Our results from both urban and rural samples thus underscore the important role likely to be played by education in determining the future evolution of the income distribution, even though the exact channels may be different in cities and the countryside.

Finally, notable by its absence in much of the discussion, is the current role played by a social safety net in providing a floor on incomes, and thus some limit on inequality. In the cities, while they may be in their infancy or under development, China has yet to develop the array of social policies with the breadth and level of other transition economies. In rural areas the primary safety net has been the egalitarian land allocation mechanism, effectively guaranteeing land to all rural households. As it turns out, the income associated with the farm income generated by this land is not enough to buffer households 
from poverty, at least when crop prices are low. None of this is to diminish the otherwise significant contribution that market reforms have made to raise overall living standards.

Our chapter is divided into five sections. In the next section (Section 2) we provide background discussion concerning the measurement of inequality. It is important to draw linkages between the distribution of welfare - which is what we are really interested in - and summary statistics of the income distribution (like the Gini coefficient). We also briefly outline the factors that we expect would contribute to changing inequality through the reform period. In Section 3 we sketch the three data sets that we use. One of the features of research in income inequality in China is uneven access to a common publicly available, nationally representative data set. Our study, like most others, uses data sets that are highly informative of trends in income distribution, but the limitations (e.g. coverage) and definitions need to be presented. Our main empirical results are presented in Sections 4 through 6. Throughout we provide separate evidence for urban and rural China, beginning with a discussion of the main trends in living standards in Section 4. Section 5 focuses on the role of geography: how important are divergent incomes across provinces for driving rising inequality? Section 6 takes a closer look at the composition and changing structure of income, providing the greatest potential linkage with the factors that may be "causing” the increase in inequality, though attribution of any changes to a particular causal factor is almost impossible given the scope of change in China over this period.

\subsection{Background and Conceptual Issues}

\subsection{Summarizing the Income Distribution}

How much better off is the Chinese population in the year 2000 compared to 1980, after 20 years of reform? Clearly it depends on who you are, and there might be one billion different answers. Our objective is to find a few numbers to summarize these billion potential answers. There are well-developed tools for aggregating the outcomes of a billion people into a single index that permits comparison of social welfare, or well-being, over time. ${ }^{1}$ Social welfare functions provide an abstract way to rank different sets of economic outcomes. Consider a billion people, each of whom has a level of "well-being" represented by his or her utility function, $u_{i}\left(c_{i t}\right)$, which assigns a level of utility to their consumption of goods and services consumed in period $t, c_{i t}$. A social welfare function could then assign a single value to the resulting distribution of happiness in the population, and will depend on each person's level of utility. While more restrictive, we could ignore the differences across individuals of their preferences, and focus instead on the distribution of consumption across the population, defining social welfare as:

\footnotetext{
${ }^{1}$ See Deaton (1997) for a summary of the various conceptual issues, and detailed references, concerning the measurement of social welfare, inequality, and poverty.
} 


$$
w_{t}=W\left(c_{1 t}, c_{2 t}, \ldots, c_{N t}\right)
$$

The evaluation exercise would thus entail collecting data on the distribution of consumption across the $N$ people living in China in 1980, calculating Social Welfare, then comparing this to Social Welfare in 2000, based on the distribution of consumption in 2000. The answer would clearly depend on our social welfare function. For example, we might evaluate welfare by the overall size of the pie, in which case social welfare would depend on the sum of consumption across individuals, or average consumption. Alternatively, we might only care about the poorest individual, and our welfare measure would only depend on the lowest level of consumption in each year.

While the answer to the "big question" thus depends on the social welfare function, a major input into evaluating the change in welfare will be the empirical distribution of consumption, or living standards, $f_{t}\left(c_{1 t}, c_{2 t}, \ldots, c_{N t}\right)$. In principle, the focus of research should thus be a presentation of summary statistics concerning the distribution of consumption. However, we also wish to learn something about how economic reforms and the evolution of institutions are linked to living standards. For this reason, while we report salient statistics concerning consumption, we focus on income instead. Does it matter? In a simple world with no saving or borrowing, consumption would equal income, and choosing between income and consumption would come down to advantages of measurement and survey design. With saving and borrowing, there are pro's and cons to using either measure (see Deaton (1997) for a detailed discussion). Consumption would probably be the preferred measure, as it is most closely linked to economic well-being, and tends to be better measured. However, we are more interested in how the income distribution has evolved, since income ultimately "drives” consumption, and it is the structure of income that we expect to be most directly affected by the economic reforms. At any event, while there are important conceptual issues thus associated with the movement from "welfare" at its most abstract to the distribution of income, for any practical purpose, the distribution of income will be a key input in the determination of the distribution of welfare.

Papers on income distribution in China, including this survey, present a series of summary statistics of the income distribution, usually focusing on means and various indices of inequality. Any inequality index, like the Gini coefficient, entails a significant distillation of potential information to a single number. Setting aside all of the data and sampling issues, it is worth reminding ourselves of the limitations associated with summarizing one billion people's economic outcomes by any single number, let alone explaining why that number has changed over time.

At a point in time, every man, woman and child in China will earn $y_{i t}$, from which they can support their consumption of goods and services. While we care about individual welfare (and income), we will assume that the relevant unit of analysis for economic decision making and welfare determination 
is the household, and that individual welfare is thus a function of household per capita income. We thus wish to summarize the evolution of the distribution of household per capita income, $y_{h t}$ :

$$
g_{t}\left(y_{1 t}, y_{2 t}, \ldots, y_{N t}\right)
$$

While we will show estimates of the entire distribution, $g_{t}$, more commonly we (like other researchers) will present only a few salient summary statistics. Mean income, $\bar{y}_{h t}$, provides an estimate of the expected income level for a randomly selected household in year $t$, and allows us to track average living standards. There are several ways to summarize the degree to which improvements in living standards are being shared. One way would be to choose a common benchmark, and see how many households had incomes rise above this benchmark. One benchmark would be a poverty-line. We could then compare the probability of being poor in 1980 to 2000. While useful, such a measure focuses only on the poor, telling us nothing about the non-poor, whether they be rich or almost poor. If average incomes are rising, and inequality is constant, we would expect poverty to fall. But poverty could easily fall while income inequality is rising, as long as average income levels are rising enough. For this reason we also want to summarize inequality. Our most common measure, reflecting the existing literature, is the Gini Coefficient. The Gini depends on the expected absolute difference in incomes between two randomly selected Chinese residents: $\left|y_{i t}-y_{j t}\right|$, and thus captures one dimension of dispersion of incomes. Understanding the evolution of mean per capita income and the Gini, with an occasional look at poverty, will thus provide most of the first order statistics necessary for an evaluation of the distribution of living standards during reforms.

\subsection{Explaining the rise in inequality}

It should come as no surprise that inequality rose as China moved from an ostensibly egalitarian socialist economy to a more market-oriented one. What is striking is how high inequality has become. Why did this happen? Are there any reasons to believe that the trends will abate? It is almost impossible to provide precise, confident answers to those questions at this point. However, we can identify a variety of factors associated with the rise in inequality, as well as describe many of the institutional changes that may be related. Understanding the distribution of income (or its changes) requires an understanding of the determinants of household income for everyone in the country. While this is a tall order, we can begin with a highly stylized expositional model of income determination at a point in time.

Suppose that a household's income can be written as the sum of income attributed to its various productive characteristics:

$$
y_{h t}=\sum_{j=1}^{K} w_{j h} x_{j h}
$$


where $x_{j h}$ is a household productive characteristic, like the level of education of the father, the time available to work of the mother, or the amount of land it has. The value, or "price," of this factor is given by $w_{j h}$, and determines how much income is generated by the father's education, the mother's work time, and household's land. These prices depend on a host of other variables, some of which will vary across households, and others which may be similar for households in the same village or city.

Between 1980 and 2000 we expect household income to change. It may change along with household endowments of productive factors: maybe education levels are increasing. However, the main changes probably occur in factor prices, or the returns to productive characteristics. Economic reforms were designed to change institutions that determined factor prices, and there is thus a mapping between institutional evolution, factor prices, and the increase in income inequality. We now briefly sketch the most important institutional and economic changes that we expect would lead to rising inequality.

\subsection{Inequality on the eve of reform}

The evolution of inequality over the course of China's economic reform cannot be analyzed without some sense of the inequality at the baseline "before" reform. We are however severely constrained in this exercise by data limitations: most data were collected after the reforms were well underway. However, we can sketch a picture of inequality and its likely sources in urban and rural areas separately, and overall. From there we can speculate as to how reforms would lead to a different distribution of income.

Prior to reform, nearly eighty percent of China's population lived in rural areas and was primarily involved in agriculture. Land was collectively farmed, with income supplemented in some periods by income from small private plots. ${ }^{2}$ Income from collective farming was allocated at the level of the production team (25 to 30 households) on the basis of both household need and accumulated work points, with the weight between "distribution on the basis of need" and "basis of labor" differing across localities and shifting over time. Overall, differences within localities between households were probably relatively small, and largely associated with differences among households in dependency ratios, i.e., the ratio of the number of individuals that worked to total household size. A host of services (health, education and welfare) were also collectively provided, which was probably equalizing. In the language of "prices” and "productive endowments”, income (and a household's standard of living) was less sensitive to productivity than would likely be the case after the reforms were started.

\footnotetext{
${ }^{2}$ Very little information exists on differences between or within localities on income earned by households from their private plots.
} 
But there was not perfect equality in rural China. There were differences across localities and regions reflecting differences in endowments and natural conditions. These differences were also exacerbated by policies of local grain self-sufficiency which helped limit re-distribution across regions. Vermeer (1982) suggests that income differences (of the portion that was collectively distributed) between richest and poorest communes (townships) may have been as high as 6:1. There was also considerable poverty in rural areas, with as many as a quarter or more of the rural population living below, an admittedly low, government-defined poverty line prior to reform (1977 or so). There was a significant geographic component to this poverty as well, with the majority of the poor located in the provinces situated in China's western provinces, running from Gansu and Ningxia, through Sichuan and to the southwestern provinces of Yunnan and Guizhou.

Incomes in urban areas consisted largely of wage earnings, and a host of subsidies and entitlements that were publicly financed but allocated by work units. Almost everyone worked in stateowned enterprises, characterized by a compressed wage distribution, relatively weak material incentives, and low returns to human capital. Differences in the standard of living between households in the same city were further limited by the rationing of many consumer goods, e.g. grain, housing, on the basis of need. Regional wage and income differences in the cities were reportedly modest and may have reflected differences in the cost of living, e.g., the cost of living was reportedly higher in Shanghai. Like the countryside, some of the largest differences between households were probably related to differences across households in their demographic composition and dependency ratios. Party members, who made up five percent or so of the population, may have also been entitled to preferential access to scarce goods and resources.

There was however a sizeable urban-rural income gap that was enforced through strict restrictions on migration from the countryside. Through the last half of the 1960s, and 1970s, the urban population did not grow much in absolute terms. Factoring in the value of a host of subsidies, Rawski (1982) suggests that on the eve of economic reform, average differences between the city and the countryside were on the order of $5: 1$ or $6: 1$, or twice that calculated excluding all of the subsidies. The gap with respect to rationed commodities was much smaller (Lardy, 1984), and a significant portion of the gap may have taken the form of higher urban-savings.

In summary, our impression of inequality before reforms is of relatively low inequality within villages and cities, a stronger regional dimension to inequality in rural areas, and a pronounced urbanrural gap. 


\subsection{Transition versus development}

While we can notionally decompose the change in income distribution to changes in the distribution of productive factors and their rewards, it is also important to recognize there are two broad, somewhat distinct, sources of these changes: transition and development. As detailed above, prior to reform, prices, including wages, and resource allocation were primarily administratively determined. Household income was determined by a set of "local” socialist institutions that mapped a household's endowment, largely consisting of labor or human capital, into income. These same institutions affected the ownership, distribution and accumulation of other forms of capital by households, such as land or physical capital.

Transition as a process entails moving to market determination of the valuation of productive endowments, and incomes. In a perfectly competitive world, incomes would be a simple product of a household's endowments and the market-determined returns to these factors. The introduction of the market affects the returns and rewards to the factors of production, for example, entrepreneurial ability and human capital. It also affects the distribution and accumulation of these same factors, though this process would take longer. Even in a stagnant, stationary world we would expect a change in factor prices moving from a socialist to market-oriented economy.

Overlaid with transition - and through no coincidence - China experienced economic development at the same time. The process of economic development and growth will also affect the returns to and distribution of factors of production in a way that matters for income distribution. For example, development may alter the relative returns of labor to capital, or increase the returns to human capital and other kinds of skills.

This discussion highlights the importance of distinguishing a "transition" effect from a development, or growth effect, at least conceptually. ${ }^{3}$ In actuality, it is impossible to separately identify these effects. However, we can use the distinction as an organizing principle for highlighting the factors we believe have been at play in three primary dimensions. These relate to the urban and rural sectors separately, and finally urban-rural income differences.

\subsubsection{Urban Inequality}

The evolution of income inequality in Chinese cities would have likely mirrored the experience in eastern European transition economies. First, liberalization in the labor market - even within the state sector - would have led to greater wage inequality. More successful enterprises could pass profits to workers through bonuses and higher base wages, so that wage inequality would rise across industrial sectors and across firms. Second, food and housing subsidies were slashed in the early 1990s. These

\footnotetext{
${ }^{3}$ Also see the (slightly) more detailed discussion in Benjamin and Brandt (1999)
} 
important forms of in-kind income were likely very equally distributed, especially compared to the straight wages that (in principle) replaced them. Third, restructuring of state-owned enterprises, the end of the "iron rice bowl” in the latter half of the 1990's led to significant layoffs, unemployment, and at least short-term inequality of access to jobs.

On top of these more transition-oriented changes, urban China was considerably affected by the development of a vibrant private industrial and service sector, with wage and employment determination entirely outside the old Socialist labor bureaus. As in any globalized developing economy experiencing significant technological change, we might expect dramatic changes in the returns to human capital and skill, which would transmit to higher inequality of earnings and income.

\subsubsection{Rural Inequality}

The Household Responsibility System (HRS) immediately permitted households to retain a greater share of the returns to their own labor and entrepreneurial talent in managing their farms. Liberalization with respect to farm sidelines and the establishment of family run businesses provided another avenue for households to potentially earn more than their neighbors. At the same time, land remained owned by the village and was allocated to households on a fairly egalitarian basis, so there was a limit to how much inequality could arise from farm incomes. The establishment of Township and Village Enterprises (TVE's), and the development of off-farm opportunities more generally, would likely have also provided households a way to earn a living off the farm, potentially generating greater differences in income across villages. While it was difficult to move from the country to the city, it was easier to move shorter distances within the countryside. These opportunities for limited migration would also have significantly changed the structure of income for households. It is difficult to predict whether this would increase income inequality, as it would depend on whether these opportunities were available throughout the income distribution.

Alongside the transition from collectivized agriculture, households in rural China also faced increasing integration with the broader Chinese economy, as well as international markets. For farmers, this generated changing terms of trade between agricultural and non-agricultural goods. Over the period of reform, especially in the latter half of the 1990's, agricultural prices declined significantly, lowering the floor provided by crop incomes, and potentially leading to a rise of inequality. Similar to the cities, industrialization and development would also have provided rising returns to human capital and skill, leading to higher income inequality. To the extent this development was uneven across provinces, it might also lead to widening income gaps across regions. 


\subsubsection{Urban-Rural Gap}

What would we expect to happen to the ratio of urban to rural incomes? From a pure transition perspective, we might expect the gap to narrow. First, the declining support of the state sector, and the end of urban food subsidies would potentially serve to reduce the heavy urban bias of government expenditure. However, these changes may have happened too slowly to matter before 2000. Through most of this period there also remained considerable restrictions on migration through the "hukou" system. While these restrictions ended recently, the constraints on mobility would have reduced the convergence of rural-urban incomes. To a limited extent, however, improvements in product and factor market linkages should have served to reduce the urban-rural gap. In the end, the evolution of the ruralurban gap depends on the relative growth rates, or development, of industrial and service sectors. To the extent that such development was concentrated in cities-possibly because of pre-existing or continuing advantages of infrastructure like schools and roads - we would expect average incomes of urban residents to grow faster than those of rural residents. And given that factor mobility remains imperfect, the urbanrural income gap could easily rise through the reform period.

In summary, there are several potential reasons why we would expect the overall level of income inequality in China to increase: It should increase within both the urban and rural sectors, and possibly across urban and rural sectors as well.

\subsection{Data}

\subsection{The data sources}

Access to well-designed, nationally representative household survey data is essential to measuring changes in the level and distribution of economic welfare. Lacking such a single data set, we draw heavily on three primary household level data sets in our analysis. For the urban areas, we obtained the National Bureau of Statistics (NBS) urban household surveys for a sub-sample of provinces including Jilin, Henan, Shaanxi, Sichuan, Hubei, Shangdong, Shanghai, and Guangdong. This survey has income and consumption measures with relatively comparable definitions for all years. We use the "income" and “consumption” variables as defined by the NBS, and included in the micro-data. These data are not without serious shortcomings. On the income side, the implicit value of subsidies associated with, for example, food coupons, is missing. These were especially important through the 1980s, but were eliminated in the early 1990s. On the consumption side, the data do not provide an easy way to measure the value of services from consumption durables, notably, housing. One other issue worth noting is that the urban data are sampled on the basis of urban household registration. This means that rural-registered 
migrants living in the cities are not enumerated, and this may have significant consequences for interpretation of urban incomes and inequality.

Our primary rural data are a series of annual household surveys conducted by the Survey Department of the Research Center on the Rural Economy (RCRE) in Beijing. We use household-level surveys covering over 100 villages in 9 provinces including Jilin, Shanxi, Henan, Hunan, Anhui, Jiangsu, Guangdong, Sichuan, Gansu. The survey spans the period 1986 to 2002, and includes between 7,000 and 8,000 households per year. The RCRE originally was intended as a longitudinal survey, following the same households over time. While there is a household-level panel dimension to our sample, we observe considerable attrition of households over the 1986-2002 period, especially after years when there was no survey. The RCRE was unable to conduct the survey in 1992 and 1994 because of funding difficulties. Households lost through attrition were replaced on the basis of random sampling.

The survey collected detailed household-level information on incomes and expenditures, education, labor supply, asset ownership, land holdings, savings, formal and informal access to credit, and remittances. That said, the construction of consistent income and consumption measures is quite tricky, especially in calculating self-supplied consumption, and the implicit flow of durables and housing consumption. Of particular importance for our purposes, especially investigating the role of geographic factors for inequality, we are able to track a panel of villages, even where there has been household attrition. This allows us to maintain geographic comparability over the complete time period.

The China Health and Nutrition Study (CHNS) data uniquely allow us to pool urban and rural households. This survey covers the provinces of Liaoning, Heilongjiang, Henan, Hubei, Hunan, Shandong, Jiansu, Guangxi, Guizhou for five years: 1989, 1991, 1993, 1997, and 2000. Because of some non-comparability issues with the 1989 survey, we only use the 1991, 1993, 1997, and 2000 data. The CHNS survey is more intensive than either the NBS or RCRE surveys. The survey provides better coverage of urban subsidies, and we believe that some sources of income - especially from non-farm selfemployment - are better measured than the other surveys. Certainly, there is more detail that can be exploited when exploring the robustness of conclusions to definitions of "income.” The CHNS does not have consumption or expenditure data, however. One especially important feature of the CHNS is that it (essentially) follows a panel of cities and villages across the survey years. We are also able to evaluate the sensitivity of urban-rural differences to the definition of "urban.” This is potentially very important when interpreting "urban and rural” results based on NBS data, where fast growing and industrializing rural areas are re-classified as urban over the transition period. 


\subsection{Issues Common to All Data sets}

There are a number of important measurement issues that need to be discussed when looking at any series of inequality measures. The estimated level of inequality can be sensitive to the definitions of income and consumption, even from perfectly implemented and comparable household surveys. Once we admit that surveys are neither perfectly implemented nor perfectly comparable, it becomes even more important to be clear how income and consumption are defined and measured. Even a simple question of how to turn household income into per capita measures can be problematic: who is a household member? In the Chinese context, should the member be defined on the basis of his or her registration status? Or, like the World Bank Living Standard Measurement Surveys, on the basis of economic attachment to the household? Should adjustments be made for the age composition of the household, i.e., should we convert household size into adult equivalents?

In the numbers that follow, we use the "best" available measure from each survey. For urban households in the NBS survey, income is defined as income earned from all enumerated sources, and household size is based on registration. For the rural RCRE households, we calculate income from all sources, including the implied market value of home produced grain. Measurement of farm incomes in China can be highly sensitive to a battery of assumptions concerning valuation, and we discuss these issues more thoroughly elsewhere (Benjamin, Brandt, and Giles 2005). These measurement issues become especially important when comparing RCRE-based results to those from the NBS, such as those reported by Ravallion and Chen (2004). Household membership in the RCRE is also based on registration. For the CHNS, we construct incomes along similar lines to the respective urban and rural surveys. For urban households in the CHNS we are also able to "value" the implicit rents associated with access to food and housing at below-market prices. With the CHNS, however, household membership is defined more on the basis of economic attachment (residency) than registration. Household members other than the head who work and live outside much of the year may not be included (though their remittances would be).

In principal, households to be surveyed are to be drawn from a representative cross-section of the population. If not, the researcher must know the sampling weights for purposes of making inferences about the population. In the case of the surveys carried out by both the NBS and RCRE, there is reason to believe that a disproportionate number of households at both ends of the income distribution, i.e. the very rich and the very poor, are being excluded. In part, this reflects the fact that survey protocol requires households to maintain diaries of their income and expenditures. This makes participation by illiterate 
households difficult, and the costs associated with record keeping for the rich high. Truncation of this sort likely leads to an underestimate of income inequality and poverty. ${ }^{4}$

A final issue worth mentioning concerns the conversion of nominal values into constant-dollar (yuan) prices. We use the official provincial CPI's to convert all nominal values into 1990 yuan. ${ }^{5}$ In order to make welfare comparisons across heterogeneous provinces, it may also be advantageous to control for differences in the cost of living. To accomplish this we use a newly constructed set of spatial price deflators, documented in Brandt and Holz (2004). These deflators allow us to adjust for crosssectional differences in urban and rural prices across provinces, and between rural and urban areas. In general, we expect incomes and price levels to be positively correlated. In urban areas, for example, the cost of the same basket of goods is more than fifty percent higher in Guangdong than it is in Sichuan. Failure to control for these differences can lead to an overestimate of inequality, and the contribution of key sources, e.g. inter-provincial or urban-rural differences.

\subsection{The Mean and Dispersion of Income over Time}

In this section we document the first-order results concerning the level and distribution of income in China: what were trends in inequality over the transition period? In both urban and rural China, mean incomes rose significantly over the reform period, as did income inequality. Below, we provide details on how the benefits of reform were shared.

\subsection{Urban}

Table 1 reports the key summary statistics of the evolution of the income distribution for four selected years: 1987, 1991, 1995, and 2001. To place these numbers in a broader temporal context, we plot the mean and Gini coefficients for all the years for which we have data in Figures 1 and 2. The NBSbased urban results are in the top panel of Table 1. Mean per capita household income grew from 1533 yuan in 1987 to more than double at 3411 yuan in 2001, reflecting steady growth of 5.7\% per year, as illustrated in the top panel of Figure 1. For comparison, Table 2 provides similar numbers based on the CHNS, with urban results in the top panel. Even though the underlying provinces, sampling frame, and income definitions are different, the urban CHNS paints a similar picture to the NBS. Mean incomes grew from 1484 yuan in 1991 to 2532 in 2000 . While the level of income is about 20 percent below the NBS,

\footnotetext{
${ }^{4}$ Benjamin, Brandt, and Giles (2005) document this in the case of a comparison of estimates of rural inequality using the RCRE data, and several other surveys in which household selection was known to be random.

${ }^{5}$ To help the reader put these real figures into current nominal estimates, the CPI roughly doubled between 1990 and 2003.
} 
the implied growth rate (over the shorter time period) is basically the same, at 5.9\% per year. In Figure 1 (Panel A), we see that the CHNS observations plot a lower, but parallel growth path to the NBS observations. Both data sets thus confirm a remarkable improvement in average living standards.

How was this growth shared? In the next rows we provide a variety of inequality measures. Table 1 shows significant increases in urban inequality as captured by NBS. The Gini Coefficient increases by almost two-thirds from 0.22 to 0.34 over this fourteen-year period. As shown in Figure 2, the increase in inequality has been quite steady over this time period, with no evidence of a slowing trend. Accounting for differences in the cost of living across cities does little to change this picture. The spatially-deflated Gini is slightly smaller, but shows similar growth between 1987 and 2001 (0.20 to 0.33). Other common measures of dispersion confirm that the inequality results are not specific to the Gini. Whichever parameter of inequality-aversion is selected, the Atkinson index shows a pronounced increase of inequality. The 90-10 ratio also rises pronouncedly by nearly eighty percent from 2.64 to 4.77 : The "rich" now earn almost five times the poor, as compared to less than three times as much in 1987. The robustness of our conclusions to the index of inequality comes as no surprise once we plot the corresponding Lorenz curves for urban incomes in Figure 3. Each curve shows the fraction of the total income accounted for by the "poorest” households. For any cumulative population's share of the "poorest" individuals (i.e., the poorest 40 percent), we see that their cumulative share of income is lower for each passing year: the rich keep getting a bigger slice. These Lorenz curves thus show a clear ordering of the income distributions as far as inequality is concerned: each subsequent reported year lies outside the previous one. So no matter what inequality index is selected, 2001 will show a higher level of inequality than 1995.

How representative is our NBS sub-sample of provinces? NBS-reported inequality figures for 1986 to 2000 using their entire urban sample show a rise in the Gini from 020 to $0.32 .{ }^{6}$ To help put the rise in inequality after 1987 in perspective, the full NBS sample shows an increase in inequality from 0.16 to 0.20 between 1978 and 1986. Clearly, inequality has been rising since the beginning of economic reforms. Turning to our comparison with the CHNS in Table 2 (and Figure 2), we see that the CHNS estimates consistently imply higher levels of inequality than do the NBS (0.38 for the CHNS in 2000 versus 0.34 for the NBS in 2001, for example), but a similar increase (in absolute terms) over years in common between the two surveys. Estimates from the China Income Project for 1988 and 1995, which address a number of important weaknesses in the NBS household survey, also reveal significantly higher levels of inequality, but a similar increase over this seven-year period. ${ }^{7}$

\footnotetext{
${ }^{6}$ See Meng, Gregory, and Wang (2004) and Ravallion and Chen (2004).

${ }^{7}$ See Kahn and Riskin (1998, 1999), for example.
} 
To gauge potential trends in poverty, our final distributional measure is the proportion of households whose income falls below one-half the 1987 median income. This line is fixed through time, providing a benchmark of how many households are raised out of "poverty," if the poverty line were set at 50\% of 1987 median income. For 1987, we see a very low proportion of so-defined "poor" households, with only 4 percent of households with low income. This proportion declines to only one percent by 2001. In Figure 4 we plot the Cumulative Distribution Functions (CDF's) for household income. On the horizontal axis we show the level of real income, while the vertical axis shows the proportion of individuals in households with an income level below that on the horizontal axis. Thus, for any "poverty line" we can estimate the proportion poor. For example, if the "poverty line" was a very high 2000 yuan (higher than mean incomes in 1987) we would see that fewer than 40 percent had incomes below this level in 2001, compared to over 80 percent in 1987. The bottom panel focuses on the bottom part of the distribution where we can select more reasonable poverty lines. Half the 1987 median per capita income level is approximately 700 yuan. Significantly fewer than 5\% of individuals had incomes below this level in any of the years, and we can see the fraction steadily declining in each year (as shown in Table 1). Higher poverty lines would show similar progress over time.

This finding can be compared with more thorough examinations of urban poverty trends by Meng, Gregory, and Wang (2004) and Ravallion and Chen (2004), which use the entire NBS sample for the period between 1986-2000, and calculate poverty lines using alternative procedures. ${ }^{8}$ The estimates of Meng, Gregory, and Wang show an uneven rise in the percentage living under poverty from two percent to about five percent in 1993, which then declines slowly through 2000. Ravallion and Chen's estimate also show a downward trend, but slightly more volatility. Despite some differences, there is general agreement on the relatively low levels of urban poverty in China based on the NBS estimates.

In the final rows of the urban-panel of Table 1, we report the consumption-based mean levels of income, and corresponding Gini coefficients. The consumption-based measures mirror the income-based ones. For urban China, it thus appears that while income inequality has increased significantly, increases in incomes have been large enough, and spread throughout the income distribution, so that almost everyone is better off than at the beginning of reforms.

\footnotetext{
${ }^{8}$ Ravallion and Chen (2004), for example, use the “official” poverty line of 300 yuan per person per year (in 1990 prices), as well as a more recently constructed poverty line based on updated minimum consumption bundles: 850 yuan for rural, and 1200 yuan for urban (in per capita terms). Meng, Gregory, and Wang (2004) also choose poverty lines based on minimum consumption bundles, as opposed to our more arbitrary - but still constant - half the 1987 median income.
} 


\subsection{Rural}

Turning to rural results, we report the distributional characteristics in the bottom panels of Tables 1 and 2, and Figures 1 and 2. The rural picture is muddier than the urban one, with conflicting evidence from different data sets. In Table 1 we report the RCRE-based results. These show unambiguous improvements in average living standards, with mean incomes rising from 920 yuan in 1987 to 1244 in 2001, an increase by about one-third. As shown in Figure 1, this corresponds to an annualized growth rate of only 2.0 percent. This is lower than most other data sets, including the CHNS, reported in Table 2. For the CHNS, income levels are approximately the same as the RCRE at the beginning of the sample, but diverge by 2000: The CHNS-based growth rate is similar to urban areas, at $6.3 \%$. Benjamin, Brandt and Giles (2005) provide a detailed discussion and reconciliation of why the RCRE growth rate differs from the NBS growth rate, explaining how differences in survey design and interpretation - especially the valuation of agricultural output - lead to discrepancies. Concerning the gap between the CHNS and RCRE, it is noteworthy that most the difference arises only after the mid-1990s, and is largely attributable to differences between the RCRE and CHNS surveys in the rate of growth of farm income. Some of this may reflect the kinds of villages that were selected, with more "suburban" villages possibly included in the CHNS, as well in how farm output is being valued. The CHNS villages may have had more acreage in vegetables and other cash crops, and been less exposed to a sharp drop in grain prices that occurred after 1995.

In the next rows we document the evolution of various measures of inequality. Our estimates reveal that inequality is slightly higher in rural than in urban areas, and that rural inequality experienced slightly smaller increases over time. As in our examination of urban inequality, spatially deflating incomes leads to lower overall inequality, but a similar trend. The CHNS data suggest higher inequality than do the RCRE data (0.46 in 2000 versus 0.37 in 2001 and 0.39 in 2002, for example), but imply a similar absolute increase over the years in common between the two surveys. A comparison with NBSbased rural inequality estimates (Ravallion and Chen, 2004) shows similar trends, but systematically higher levels of inequality in our two surveys. Using the NBS estimates to extrapolate would also put the Gini coefficient for rural inequality in 1980 in the vicinity of 0.30 .

As illustrated in Figure 2, much of the increase in rural inequality in the two rural data sets occurs in the late 1980s-early 1990s, and then again beginning in the late 1990s, with inequality actually falling in between. An important reason for this is the behavior of farm prices. Between 1993 and 1995, farm procurement prices doubled in nominal terms, and by fifty percent relative to the rural CPI. This disproportionately benefited low-income rural households for whom farming was an important source of income, and helped to offset the impact on inequality of the rapid growth of non-agricultural incomes. Without this increase in farm prices we would have observed a more sustained increase in rural 
inequality. There was a reversal of fortune for the poorest households in the last half of the 1990s, which can be linked to falling farm prices and the behavior of farm incomes. Not until 2002-2003 did farm prices and incomes begin to recover.

In Tables 1 and 2 we report rural inequality for different inequality indices. As for urban areas, all the indices show rising inequality, so our conclusions are not specific to the Gini coefficient. The Lorenz curves in Figure 2 also unambiguously show that inequality is higher in 2001 than 1987. However, there is a less clean ranking of 1987 and 1995, as the Lorenz curves cross, and essentially lie on top of each other over much of the distribution. In principle, this means that inequality comparisons between 1987 and 1995 may be sensitive to the choice of inequality index. Indeed in Table 1, 1995 is ranked more unequal than 1987 for all indices, except the 90-10 ratio.

A crucial question for welfare analysis is thus whether the increase in mean incomes was high enough to offset the increased dispersion of incomes. While the rich got unambiguously richer, what happened to the poor? At the bottom of Table 1 we report the percentage of households below the 1987 median. These estimates show uneven progress, with a rise in the late 1980s followed by a sharp drop through the mid-1990s, but then an increase through the end of the decade. By 2001 only 11 percent of households had incomes below one-half the 1987 median income, compared to 16 percent in 1987. Given the perception of rapid growth in the country-side, this decline in "poverty" seems disappointing. The stagnation in this dimension is a feature of the late 1990's. Figure 4 shows the CDF's for rural areas for three selected years. Lower CDF's correspond to "better” income distributions, with fewer individuals having incomes below any given level. The 1987 CDF is clearly highest over most levels of income. As seen in the bottom panel, however, the CDF's for all three years are indistinguishable below incomes of 200 yuan. There are similar - very low - percentages of individuals with incomes this low. The income distribution has thus generally improved since 1987. It is less clear comparing the present to 1995. The top panel shows that the CDF's for 1995 and 2001 cross below incomes of 2000 yuan. For incomes below 1000 yuan per year, the 1995 CDF is lower than for 2001. Thus, even for a very high "poverty line” or benchmark, the 1995 income distribution dominates the 2001 distribution. The increase in inequality over the 1990's thus has the poor getting poorer, with a decline in absolute living standards. These results are not simply an artifact of the RCRE. The CHNS-based numbers in Table 2 confirm the stagnation of incomes of the poor since 1997.

It would be a mistake, however, to conclude that economic reforms have entirely missed the poor. Part of the problem stems from our use of the RCRE data which only begin in 1986, and fail to capture the enormous gains in reducing poverty in the late 1970s and early 1980s following the introduction of the Household Responsibility System, and rural reform. Subject to limitations in the NBS data, especially for the pre-1984 period, Ravallion and Chen's (2004) estimates show the percentage of rural residents 
living under poverty fell from $76 \%$ in 1980 to $22 \%$ by 1987 . Most of the gains made by the poor thus occurred before the first observation of our RCRE sample. With sixty percent of China's population still classified as rural, these estimates also highlight that much of China's poverty remains in the countryside. And the clear stagnation of rural incomes, especially for those in the bottom half of the distribution, suggests little positive news for the short-run prospects for rural poverty alleviation.

In the final two rows of the rural panel of Table 1, we report the consumption-based means and Gini coefficients, to explore sensitivity of our results focusing on income. While a significant part of the consumption is measured independently of income, for the rural data both income and consumption contain a common component of self-consumed home-production. Still, it is re-assuring that the consumption-based measures show the same trends as the income-based measures. For rural China, unlike in the cities, it thus appears that increases in inequality do off-set the otherwise rosy picture painted by rising mean incomes, at least for those at the bottom of the income distribution.

\subsection{The Role of "Geography"}

The role of widening regional income differences and their contribution to increasing inequality is a common theme in the literature on inequality in China. ${ }^{9}$ Rising disparities between localities, especially provinces (inland versus coastal, for example) are often seen as the most important source of the rising income differences we just documented, as some provinces are better situated to take advantage of market liberalization and reforms related to foreign trade and investment. In rural areas, spatial differences may also be present due to differences in per capita land endowments, access to urban markets, and initial conditions at the time of the reform (e.g., the level of development of commune and brigade-run enterprises). With decline in the importance of restrictions on migration enforced by China's residential registration system (the hukou system), and opening up of markets for migrant labor, however, we might expect some degree of regional convergence, and a decline in the "contribution" of region to overall inequality. Our samples, which include the rapidly growing coastal provinces of Guangdong and Jiangsu and slower growth interior provinces of Sichuan and Gansu, seem reasonably well suited for examining these differences and their trends, as well as for understanding the role of geography in affecting income inequality more generally.

\footnotetext{
${ }^{9}$ Kanbur and Zhang (1999) provide an excellent overview of the literature on regional inequality, highlighting inland versus coastal, and urban versus rural dimensions. See also Gustaffson and Li (2002).
} 


\subsection{Spatial Income Decompositions}

There are a number of approaches we can take in decomposing inequality across regions. Unfortunately, the Gini coefficient is not readily (or neatly) decomposed. Instead, a simple strategy entails decomposing the variance of log income (itself an inequality index) by estimating the following regression:

$$
\ln y_{i}=D_{L}^{\prime} \gamma+u_{i}
$$

where $D_{L}$ is a vector of dummy variables indicating the location of individual $i$. The R-squared from this regression indicates the proportion of the variation (or variance) of $\ln y_{i}$ that is explained by the location dummies. The remainder is the (within-location) residual variance of log income, and a measure of the degree to which household income is not explained by the average income of its neighbors. ${ }^{10}$ We carry out this exercise separately for urban and rural households.

Table 3 reports the results of the spatial decomposition using each of our data sets. We define location at two-levels of aggregation: the city (or village) and province. We estimate the above regression separately for urban and rural samples, with province and city- (or village-) level dummies. We also distinguish between spatially deflated and un-deflated household income, exploring the extent to which spatial income differences are attenuated when accounting for differences in the cost of living. ${ }^{11}$

The first row shows results for urban China, and the fraction of household income differences that can be explained by province. In 1987, mean differences in provincial income explained only 26 percent of the variation in household income. The majority of inequality was thus due to differences of income among households in the same province. Note that this does not mean the effect of location is inconsequential: The R-squared from this regression is higher than most human capital earnings functions! Province of residence thus explains as much of the variation of income as does age, education, and other individual characteristics for individual earnings. ${ }^{12}$ The point we wish to emphasize, however, is that the majority of income inequality cannot be explained by location. This means that a focus on geography as the key driver of rising inequality is misplaced. Local institutions, and differences in the characteristics of, or opportunities for, people living in the same community, are more important.

\footnotetext{
${ }^{10}$ For comparability, we also decomposed the Theil Index (which is neatly decomposable), and found similar results.

${ }^{11}$ For our extracts of the urban NBS data, the city indicator is only available after 1993.

${ }^{12}$ Consider another "benchmark" for a high or low contribution of geography in a spatial decomposition. We replicated this procedure using a Canadian household survey (the 1996 Family Expenditure survey). Even though there are significant differences in provincial incomes (for example household per capita income is about 15 percent higher in Ontario than Quebec, the two most populous provinces), "Province" only explains $1.5 \%$ of the variation in log per capita household incomes in Canada: within-province income inequality is $98.5 \%$ of Canadian income inequality. While low in an absolute sense, the contribution of space to income inequality is thus much higher in China than Canada, and probably most other developed countries.
} 
Continuing through the first row of Table 3, our estimates suggest an increase in the role of province up through the mid-1990s, followed by a decline. The sharp increase in the first half of the 1990s may be linked to the elimination of numerous subsidies enjoyed by households, which were less than fully compensated in some provinces by an increase in cash wages (Meng, Gregory, and Wang, 2004). ${ }^{13}$ Unexpectedly for us, the massive layoffs in the SOEs, which began in the mid-1990s and had a significant regional component, did not result in an increase in the role of spatial differences through 2001. Less surprising, spatially deflating the data lowers the contribution of "location", but the trend is otherwise very similar. Overall, a quarter to a third of urban inequality can be linked to the province in which a household is located, with a slightly higher percentage (40 to 50 percent) attributable to the city. In the bottom panel we report results from the CHNS data. In the CHNS, city and especially province play a less prominent role than in the NBS sample, with the role of city declining over time.

Turning to the rural sector, aside from a slight increase in the early 1990s, the RCRE data imply a fairly steady decline in the role of location in overall inequality. Spatially deflating has an effect similar to what we observed in the urban data, and lowers the role of location considerably. By the end of the period we are analyzing, both the RCRE and CHNS data suggest that province of residence explains only about 10 percent, and village between 30-40 percent, of rural inequality. Most of the inequality in China is within the villages and cities in which Chinese households live and work.

\subsection{Urban and Rural Inequality}

So far we have looked at rural and urban inequality in isolation. Yet one important dimension of rising inequality may be a widening gap between urban and rural incomes. Certainly, these income differences have figured prominently in the literature. Lacking access to the NBS rural household survey data, the CHNS is the only data set that allows us to explore “overall inequality,” pooling urban and rural samples. The CHNS thus permits a formal decomposition of spatial inequality that includes allowance for provincial or urban-rural income gaps.

We report summary statistics for the pooled urban and rural sample in Table 4. Between 1991 and 2000, real per capita income rose from 1121 RMB (in 1990 prices) to 1912 RMB, which implies an annual increase of just slightly less than 6 percent per annum. Perhaps surprisingly, pooling the urban and rural samples leads to an overall level of inequality no higher than the rural sample alone. By all measures, inequality increased considerably, with the Gini coefficient increasing from 0.37 to 0.44 , and the 90-10 ratio rising from 6.93 in 1991 to 11.04 in 2000. The absolute increase in (and level of)

\footnotetext{
${ }^{13}$ An alternative possibility is that the NBS data do not fully capture differences across provinces in earlier years in these subsidies, which would have led to an underestimate in the role of province in the decompositions.
} 
inequality is the same as estimated for the rural sector alone, but slightly smaller than the increase occurring in the urban sector. The behavior of the Gini coefficient for this sub-sample of provinces is actually identical to that calculated by Ravallion and Chen (2004) using the entire NBS sample, so it is unlikely this conclusion is an artifact of the CHNS.

In the bottom half of Table 4 we report the results for spatial decompositions that provide estimates of the contribution of location and urban-rural differences to overall inequality. The role of province and city (village) in overall inequality is similar to our estimates for the urban and rural sectors separately using the CHNS. By the end of the period we are analyzing, the city or village that a household lives in only explains about a sixth of the inequality, and province only five percent.

Controlling for the role of provincial differences in mean incomes, we also look at the contribution of urban-rural income differences to overall inequality: How much do mean differences of income between urban and rural households contribute to overall inequality? We do this by including in the spatial decomposition regression province dummies, an urban indicator, and interactions between the province and urban dummies. The interactions allow the urban-rural gap to vary across provinces. To help in the interpretation, the average urban-rural income gap in the CHNS sample (implied in Table 2) is 1.6. Combined, province plus the urban-rural distinction explain only about fifteen percent of total inequality, or an increase of ten percent over that explained by province alone. The contribution of these two geographic dimensions to total inequality is also relatively constant over the period. Our estimates imply that an average urban-rural income gap of 1.6 is actually responsible for only a small part of the inequality in incomes. These results once again point to the significant contribution of differences within urban areas and the countryside to current inequality in China.

This result is counter to conventional wisdom that rural areas are being left behind. Interpreting the behavior of urban-rural income differences can be tricky however, largely because of their sensitivity to the definition of "rural." Many publicly reported urban-rural gaps - especially trends - may be a statistical artifact, and driven by systematic selection of poorer areas as "rural." This is especially important in the Chinese context because the NBS-based urban-rural comparisons allow for rural areas to be reclassified as urban. If a rural area develops enough, it is "promoted" to urban status. While this makes sense at a point in time, it destroys comparability with the past. By construction, the urban-defined population is in the faster developing areas, even if a previously defined rural area was developing. This serves to select the remaining rural sample from the more "stagnant" areas. Since the late 1970s, the share of the Chinese population that is urban has roughly doubled, a major portion of which is the result of reclassifying rural areas to urban. We use the CHNS to illustrate these points in Table 5, comparing the levels and growth rates of incomes in rural and urban areas across alternative definitions of urban/rural. 
The first definition holds constant a location's rural-status throughout the period. We use the CHNS designation of "rural," plus "suburban” clusters to construct our first rural indicator. This approximately corresponds to a definition based on household registration, i.e. in 1990 households in these clusters had rural registration. One important feature of this definition is that the rural-urban status is held constant through 2000. So, even if a rural area completely paves over its farms and industrializes, it will remain "rural". This definition allows rural areas to develop, and stay "rural." The second definition is based on economic structure, and is malleable over time. We define localities as rural if most of the households are farmers. Specifically, a locality is rural if fifty percent (or more) of the households earn fifty percent or more of their income from farming. A village that industrializes between 1991 and 2000 will thus switch its classification from rural to urban. This isn't exactly the same as what the NBS does, but it mimics similar reclassification procedures.

Several findings emerge. First, the urban-rural gap is higher with the second definition, being close to two-to-one. This is not surprising, as the "urban" clusters are positively selected on the basis of having more developed non-agricultural income sources. The ratio for our first definition is around 1.5. Second, with definition one, the urban-gap is generally (and slowly) falling (though there are big year effects that cloud the trend). Again, definition one allows "successful", fast growing rural clusters to retain "rural" league status. Systematic reclassification hides the actual convergence that may be occurring between town and country. And third, the growth rates are higher for both urban and rural under definition one. The "rural" growth rate is less than two thirds as high under definition two, as "successful” villages are systematically dropped. The urban growth rate is also lower under the second definition (0.046 versus 0.059 ). This may seem puzzling, except that the relatively rural, formerly "rural” clusters are poorer than the originally urban clusters. The newly "promoted" urban clusters continuously lower the average "urban” income. In summary, people living in rural areas are keeping up with those living cities, though they undoubtedly remain poorer.

\subsection{Inequality Dynamics: Interior versus Coast}

Regional differences play a relatively small role in the overall changes in inequality we observe. This does not preclude the possibility of differences in the dynamics of inequality between regions that may be important in their own right, and possibly linked to the growth process. Geography may matter in more complicated ways than generating differences in mean incomes. The focus on coastal versus inland economic outcomes may be justified, though for more subtle reasons. In Table 6, we provide summary data on incomes, inequality and the results of a spatial decomposition for the coastal and interior regions separately using the CHNS for the 1990s. Coastal here includes the provinces of Liaoning, Shandong, Jiangsu, and Guizhou, while interior includes Heilongjiang, Hubei, Henan, Hunan and Guangxi. In 1991, 
mean incomes in the coastal provinces were only modestly higher than they were in the interior, with both urban and rural incomes in the coastal areas higher than their counterparts in the interior. Over the decade, the difference in average incomes between the two regions widened considerably, with mean income in the coastal provinces 2215 yuan by 2000 compared to 1652 in the interior, or a difference of a third.

Much of the increase in the gap, however, appears to be the result of a growing difference in incomes between rural households in the coastal and interior provinces. By 2000, rural incomes in the coastal provinces are nearly fifty percent higher than they are in the interior. On the other hand, there are only modest differences in the rate of growth of incomes of urban households in the two regions, and the ratio of mean or median urban incomes in the two regions remains more or less constant over this period. The failure of incomes in the interior to keep up with coastal areas appears to be a rural phenomenon.

Differences in the behavior of inequality in the two regions are equally telling. Not only is the level of inequality higher in the interior, but the increase through the 1990s is greater as well. In the coastal provinces, inequality increases from 0.35 to 0.39 , with the increase occurring largely in the early 1990s. In the interior, it increases from 0.39 to 0.48 . The significantly larger increase in the interior can be attributed to two key factors; first, the more rapid increase in inequality in rural areas in the interior compared to the coastal provinces; and second, a widening rural-urban income gap in the interior compared to the coastal areas. In the interior, rural inequality increases from 0.40 to 0.49 , but in the coastal provinces inequality remains more or less the same (just under 0.40 ). In the interior, on the other hand, the rural-urban gap widens from 1.58 to 1.85 , while in the coastal provinces it falls from 1.60 to 1.32. Partially offsetting some of this is the more rapid increase in urban inequality in the interior.

Several of these same trends are also mirrored in mean provincial urban and rural household incomes reported by the NBS, and provided in Table 7. We attribute to everyone living in urban (rural) areas in a province the same mean per capita income, and use the urban-rural spatial deflators and population weights to construct a mean provincial income. We then use the NBS data and our constructed estimates to look at inequality in mean provincial urban and rural incomes within the two regions separately, the differences in urban-rural incomes, as well as inequality in mean provincial incomes in the two regions. This simulation exercise sets inequality to zero within the urban and rural sectors of each province. Significantly, the pooled Gini is both higher, and rises more rapidly in the interior than it does in the coastal provinces. The primary source of the difference in the behavior between the two regions is the failure of rural incomes in the interior to grow as rapidly as the urban incomes. While the NBS data may suffer from some of the re-classification bias we discussed earlier, we observed the same phenomenon in the CHNS (in Table 6).

How might we explain these differences in the behavior of the inequality between the two regions? There is a potential link with the paper in this volume by Brandt, Hsieh and Zhu (2005) on 
growth and structural transformation in China, and the influence of the size of the state sector on the absorption of labor out of the countryside. At the outset of the reforms, the role of the state sector was significantly more important in the interior than in the coastal provinces. Some of this reflected the policy of the Third Front, and a redirection of much of China's industrial investment to the interior in the 1960s and 1970s. With reform, the growth of the non-state sector in the interior provinces has been much slower as more resources went to support a larger population tied to state sector in the urban state sector. This has handicapped the growth in rural incomes through the demand for labor in a host of secondary and tertiary industry in both the urban and rural sectors. ${ }^{14}$ As we shall see, the most significant source of growth for rural households has been in non-agricultural activity, especially off-farm wages and family businesses. Although migration to coastal provinces has relaxed some of these constraints, it can be argued that expansion in these opportunities has been more seriously constrained as more resources have been tied up in the interior provinces in supporting an inefficient state sector. In contrast, growth in the non-state sector in the more dynamic coastal provinces has helped to keep the urban-rural income gap from rising, but has also provided a wide array of opportunities to households that has prevented a sharp deterioration in rural inequality as observed in the interior.

So geography does matter. However, the story of rising inequality in China is not dominated by divergence of incomes between rich and poor provinces. Economic opportunity clearly varies across regions, and this undoubtedly affects the development of rural areas. However, a considerable amount of inequality exists, and has been rising, within each of China's regions, however we define them.

\subsection{The Composition of Income}

If two households were selected at random from the same village (or city) in 1980, and then again in 2000, we have seen that the expected absolute difference in their incomes has unambiguously risen. Why? Addressing this question requires a careful analysis of the evolution of institutions that map household endowments into family income, and is a significant research enterprise in itself. Our more limited objective here is to sketch some of the correlates of the within-village or city inequality, particularly those related to the composition of household income. We also present some explorations of other potential correlates of widening income differences between households.

Studying the composition of income provides a direct estimate of the changing economic structure. For example, how important is non-farm self-employment to rising rural incomes, and to what extent is unequal access to such opportunities a driving force in rising inequality? In cities, has self-

\footnotetext{
${ }^{14}$ They find at the provincial level that the reallocation of labor from agriculture to non-agriculture is inversely related to the size of the state sector at the time of the reform.
} 
employment also grown, especially with SOE reform? We report the results of two exercises that summarize the changing composition of income. The first is a straightforward decomposition of mean incomes. Household i's income, $y_{i}$, is the sum of its income from $K$ various sources, $y_{i k}$, (some of which may be zero):

$$
y_{i}=\sum_{k=1}^{K} y_{i k}
$$

Mean household income is thus given by:

$$
\bar{y}=\sum_{k=1}^{K} \bar{y}_{k}
$$

A one-percent increase in mean income from source $k$ will increase mean household income by:

$$
w_{k}=\bar{y}_{k} / \bar{y}
$$

the average share of income source $k$ in total income. Our first exercise thus reports the changing composition of the levels of income.

The second exercise reports the decomposition of income inequality. What fraction of income inequality can be attributed to inequality of income source $k$ ? Our key tool for this analysis is the decomposition proposed by Shorrocks $(1982,1983)$. The Shorrocks decomposition for a particular source of income $k$ yields $s_{k}$, defined by:

$$
I(y)=\sum_{k=1}^{K} s_{k} I\left(y_{k}\right)
$$

For any income source $k, s_{k}$ is the proportion of the Gini (or any other inequality index, $I(y)$ ) "caused" by inequality in the distribution of $y_{k}$. Obviously, increases in the inequality of any given income source will lead to an increase in overall income inequality. The Shorrocks decomposition, $s_{k}$, differs from the share of the income source $w_{k}$, because it accounts for the correlation between the income source, and total income. Certain income sources tend to be earned by the rich or poor. An increase in the inequality of income earned by the rich will increase inequality by even more than its share in total income, if the spread in income leads to more of that income going to the rich. Similarly, an increase in inequality of income earned by the poor could, in principle, reduce overall inequality if it increased the relative incomes of the poor. This would lead to a negative $s_{k}$, which almost never happens. For our purposes, we view $w_{k}$ as a reasonable benchmark for $s_{k}$. When $s_{k}>w_{k}$, then inequality of income source $k$ contributes more to inequality than it does to mean income, which we denote as a disproportionate effect on inequality. In other words, if income from family businesses comprises 10 
percent of average income, but inequality of family business income contributes 20 percent of inequality, we will conclude that family business income has a disproportionate effect on inequality.

\subsection{Urban Incomes}

Table 8 provides a summary of the structure of urban incomes, as well as the Shorrocks decomposition, using the NBS data. We show results from the beginning and end of our sample to illustrate trends in the composition of income. In 1987, wages comprised 86 percent of income, and were by far the most important component of urban incomes. However, as recorded by the NBS, wages do not appear to include many of the subsidies that urban residents received, including access to goods and services at below market prices, as well as the value of the in-kind component of incomes. These were especially important in the 1980s, and then declined sharply in the early 1990s. The NBS numbers thus probably understate the importance of having a wage job. In 1987, the Shorrocks decomposition shows that while comprising 86 percent of total income, inequality of wage income only explained 66 percent of total income inequality. While higher wage inequality obviously increases overall inequality, the increase is lower than its share of total income. In 1987, wages were thus relatively equalizing (compared to other sources of income). By comparison, when we move to 2001 we observe a small decline of about ten percent in the percentage of households with wage income, and an even larger decline in the percentage of income coming from wages, to 68 percent. This is partially offset by modest increases in the share of income from self-employment (still very small in the NBS data), and pensions. By 2001, more than a third of all urban households report pension income, with pensions the source of nearly twenty percent of all income. The notable change in the Shorrocks decomposition is that while wage earnings are now a smaller share of total income than in 1987, they now account for an even larger share of income inequality. Understanding urban inequality, and the rise in urban inequality, thus demands an understanding of changes in the labor market, and the determination of individual earnings.

Given the potentially important role of food subsidies, and also the possible under-estimation of family business income in the NBS data, we repeat the exercise using the CHNS data. The income categories will not be identical, but broad and rough comparisons are still helpful. The CHNS data provide a much better picture than do the NBS data of the role of subsidies, including access to major consumer goods (primarily food) and housing at below market prices, childcare, etc. These subsidies typically were allocated in a fairly egalitarian way to urban residents, often through employers, and in 1991, represented a full quarter of a household's average income. Between 1991 and 2000, they declined in absolute terms by more than half, and by a factor of four when measured as a proportion of income. ${ }^{15}$

\footnotetext{
15 The decline in these subsidies was precipitated by fiscal problems of the central government. By the early 1990s, urban subsidies reportedly represented a quarter of all central government expenditure.
} 
The Shorrocks decompositions also confirm that these subsidies contributed very little to overall inequality, and were relatively equalizing. The decline in these subsidies almost certainly helped contribute to growing inequality. The CHNS data show a smaller share of urban income coming from wages, though some of this may reflect the aggregation of subsidies into the NBS wage income. That said, wage income is still the most important source of income, and the largest contributor to urban income inequality. One further striking feature of the CHNS, in contrast to the NBS data, is the importance of income from family businesses. The estimated share of income from self-employment is higher in the CHNS (10 percent versus 5 percent), while in 2000 it contributes to over one third of overall inequality. This helps account for the higher level of urban inequality in the CHNS, and underscores the limitations of NBS survey data in collecting income on family enterprises.

But earnings inequality is still the main story in cities. It is important, however, to note that there are several potentially important dimensions to wage earnings. As explained in detail in Cai, Park, and Zhao (2005), urban labor markets underwent considerable change, even over the most recent 15 years of reform (since 1990). Enterprise reform, especially in SOE's, may have contributed to widening differentials in wage rates across firms and individuals. Workers lucky enough to work in successful enterprises would see their wages grow faster than those in poor performing firms. ${ }^{16}$ Private sector firms would be more likely to pay on the basis of individual productivity, generating further inequality of wages. With the increase in the layoffs from the state sector beginning in the mid-1990s, and with over 40 million now laid off in industry, we might expect some of the growing dispersion in incomes to be coming from a shift into the lower paying self-employment or perhaps early retirement for some individuals and households. In short, some of the rising inequality of wage earnings may have arisen as some people's wage earnings fell to zero (Meng, 2004). Even among those households with working members in the wage sector, an increase in wage earnings inequality could be coming from either growing differences in time worked (days, months, or weeks), or wage rates per unit of time.

In Table 9 and Figure 5 we use the CHNS urban data to look at this dimension of urban inequality more carefully, and evaluate the relative contribution of "wages" versus "hours” to overall earnings inequality. The top half of Table 9 provides measures of the inequality of wage earnings, first over all households, and then over only those reporting positive wage earnings. For all urban households, the Gini coefficient for earnings rose from 0.49 to 0.67 , an increase of almost 50 percent. Some of this increase was driven by the growing number of households without any wage earnings. In the second panel, we see that the proportion of households with positive wage earnings fell from 75 percent in 1991 to 58 percent

\footnotetext{
${ }^{16}$ Yuen (2000) confirms that the tighter connection between SOE performance and worker wages led to greater dispersion in wages.
} 
in 2000. This significant drop probably reflects the layoffs associated with SOE restructuring, and may be a transitory outcome, as opposed to a long run trend.

Figure 5 expands on these proportions, plotting the wage-employment rates by age category, for men and women separately. To what extent is the decline in wage employment (and thus wage income) concentrated among certain cohorts, especially the elderly? We observe significant reductions in wage employment for all age groups beginning in the mid-1990s, that are especially severe at the tails of the age distribution (20-30,50+) for men, and for prime-age women (20-40) that are likely related to labor market and SOE reform. It turns out that these declines are paralleled by similar reductions in labor force participation rates (in all types of work), so that the percentage of individuals that work in wage employment (among those working) actually remains fairly constant over time. What is most striking, nonetheless, from Figure 5, is the huge drop in access to wage jobs for the youngest cohorts. While the elderly clearly have plenty to be concerned about, it is poor job prospects for twenty to thirty years olds that may have the longest run adverse impact on welfare.

Returning to Table 9, continuing in the second panel, we see that earnings inequality still rose among those with positive earnings, with the Gini rising from 0.32 to 0.42 . How much of this rise is due to quantity worked, as opposed to the returns? In the bottom part of Table 9, we provide a simple decomposition of the log of wage earnings for those households with positive wage earnings into constituent log months worked and log monthly wages, as well as the covariance between the two. We express the results in levels, as well as the percentage of the total variation explained. ${ }^{17}$ Over the entire period, the variance of the log of wage earnings for those households with wage earnings increased by more than fifty percent. In 1991, 53.1 percent of the variance can be attributed to the variance in the log of months worked, with the variance in the monthly wage explaining 39.2 percent. Over the ten-year period between 1991 and 2000, there is not much of a change in the dispersion of months worked, however there is a more than doubling in the variance of the log monthly wage. Indeed, most of the increase that we observe in the dispersion of average annual wage earnings can be attributed to an increase in the dispersion of average monthly "wages." As important as access to jobs may be in generating rising inequality, rising wage inequality among those working the same number of months is also an important element of the story.

As documented in Cai, Park, and Zhao (2005), one the likely source of the increase in wage inequality is the increase in the rate of return to human capital. Park, Song, Zhang, and Zhao (2003) also show that no matter how you partition workers into groups (e.g., high and low educated, old or young), wage dispersion has also increased dramatically. This residual inequality - while poorly understood - is labeled inequality due to "unobserved skill." It is not surprising that that the returns to unobserved

\footnotetext{
${ }^{17}$ We carried out the same exercise using days rather than months, and obtained very similar results.
} 
productivity should rise through the reforms. From a policy perspective, however, the returns to schooling are more interesting. Over the 1990s, the average rate of return to an additional year of education increased from 4 percent to more than 10 percent. The increase in return was also not realized uniformly over years of educational attainment; in other words, the percentage increase in wage earnings resulting from an additional year of school was not the same for some one with a middle school degree (9 years) and a high school degree (12 years). In fact, it appears that a significant amount of the increase was realized by those with university degrees, as wage earnings of those with a university degree increased significantly relative to someone with only high school degree.

If the distribution of education (or human capital) was immutable, then rising returns to schooling might lead to ever widening income gaps. As documented by Behrman, Hannum, Wang (2005), however, educational attainment is rising quickly in China. In Figure 6 we use the CHNS to plot the age-education profiles for men and women in urban (and rural) China. Two important patterns are confirmed. First, is the clear increase in educational attainment for both men and women, across the age distribution. It isn't only the young benefiting from increased investments in schooling. Subsequent cohorts of prime and middle-aged individuals are also showing the fruits of investments in education made prior to reforms. Second, while men's schooling attainment remains higher than women, especially for older cohorts, the improvement in schooling levels has been greatest for women. From the perspective of predicting trends in future inequality, a key determinant will be whether the increasing supply of educated workers is enough to off-set the increasing demand for educated workers. If it is not, we can expect to see further rising returns to schooling, and widening income inequality. If supply increases fast enough, we might instead see an attenuation of the growth in wage inequality, as is believed to have happened in other Asian economies (Birdsall, Ross, and Sabot, 1995).

In our final exploration of urban income inequality, we examine the role of age - or cohort - in rising inequality. To what extent is there an age dimension to urban poverty? For example, are the elderly being left behind? In Figure 7 we plot log household per capita income by age group by year, using the CHNS. The plotted lines mirror the means shown in Table 2, with significant growth in average incomes between 1991 and 2001. Until age 60, incomes seem to rise with age. Clearly, however, the incomes of those 60 and older are lower than those younger, and the gap has been persistent over time. That said, the per capita incomes of the elderly have been improving like everyone else's, so while they may not be as rich as those who are presumably still working, the elderly in China's cities appear to be sharing in the general improvements of living standards. 


\subsection{Rural Incomes}

If labor markets lie at the heart of rising urban inequality, what are the most important factors behind the slower changing, but higher level of inequality in rural areas? Previous studies have emphasized the role of non-farm income in contributing to rising rural inequality, especially departing from the relatively equal world of farm incomes derived from an egalitarian land distribution. ${ }^{18}$ The bottom panel of Table 8 provides data for the composition of rural incomes for 1987 and 2001 using the RCRE data. For 1987, income from farming, including both cropping and agricultural sideline activity (animal husbandry, forestry and fishery) was the source of more than half of all income, with participation in farming and farm sidelines nearly universal among households. This reflects the fact that nearly all households in rural China were allocated land. By itself, income from grain was thirty percent of total household income. Family business, mostly in commerce and services, comprised 16 percent of income, while wage income was the second largest overall component, at 25 percent. Most wage income in the 1980s was earned locally, within the village or township, with more than two-thirds of all households reporting income from wages.

This structure of income changed dramatically by the end of the period, with much of this occurring in the late 1990s. Especially noteworthy is the sharp drop in the percentage of income coming from agriculture, mostly crop income. A significant portion of the decline can be linked to the sharp drop in farm prices beginning in the mid-1990s. Currently, agriculture and agriculture sidelines combine for only thirty-one percent of total household income. We also see an increase in the relative importance of income from family businesses, which rose from 16 to 20 percent as a share of total income. But the largest improvements in family income came from wage earnings, especially wages earned by temporary migrants. ${ }^{19}$ Locally earned wages have become less important in both relative and absolute terms, while employment opportunities outside the village and accessed through migration have become a more important source of labor earnings.

Turning to the Shorrocks decompositions for 1987, we find that agricultural income, while disequalizing, contributed much less to overall inequality than its share of total income (13 percent versus approximately 40 percent). ${ }^{20}$ The same applied to agricultural sidelines, so that combining all agriculturerelated sources, only 20 percent of total inequality was attributed to inequality of agricultural income,

\footnotetext{
${ }^{18}$ See Benjamin, Brandt, Glewwe and Guo (2002) for a survey of these studies, e.g., Hare (1994).

${ }^{19}$ The wage earnings of temporary migrants include household members resident in the village, but who commute outside the village to work and return on weekends, as well as wage earnings brought home by locally registered household members who work outside the village for a substantial portion of the year. The RCRE survey does not permit a further disaggregation.

${ }^{20}$ Elsewhere (Benjamin, Brandt, and Giles, 2005) we have carried out the same decompositions controlling for location, which rarely matters. This indicates that composition of income matters within-villages much the same way as across villages.
} 
even while this source accounted for 53 percent of total income. For 2001, agricultural income excluding sidelines was almost irrelevant to inequality: while it still comprised 21 percent of income, it accounted for only 6 percent of overall inequality. It was very hard to get rich farming. This reflected the low crop prices already mentioned, as well as constraints on farm size implicit in the administrative allocation of land.

We explore the land distribution more specifically in Table 10. Here we report the Gini coefficient, as well as the 90/10 ratio for per capita managed land. Land inequality did grow from 1987 to 2002, but it is still quite low by developing country standards. The Gini in 2002 was 0.48 . Note that unlike incomes, however, much of this inequality reflects differences in farm size across space: 70 percent of the variation in farm size is explained by village dummies, and over 30 percent by province. Even across space, land area is a poor measure of the land endowment, given the usual negative correlation between land quality and farm size. For example, in some areas land can be multiple-cropped (farmed more than once a year). Farm sizes also tend to be smaller in these areas, so "farm size" understates a household's "land capacity." The spatial decomposition based on cultivated area alone will thus exaggerate differences in land across space. Still, there is only limited (but non-zero!) effective land inequality within villages. That largely explains why farm income contributes so little to overall inequality: farm income is quite equally distributed. It is worth noting, however, that equality of farm income, even as a consequence of the egalitarian land policy does not imply that the land distribution policy is necessarily good for overall income inequality. More inequality of farm income might actually reduce overall income inequality. While not quite negative, the Shorrocks decomposition is close to zero. Especially if low income households have poor non-farm alternatives, it would be to their advantage to specialize in farming, thus leading to more inequality of farm income (and less total inequality). And unequal access to non-farm opportunities matters more than ever.

In 2001, agricultural sidelines (like raising livestock) explain 18 percent of inequality, higher than the 10 percent of income they represent. Wage income, however, was the single largest contributor to overall inequality, with 44 of overall inequality explained by inequality of wage earnings. This is only slightly larger than the now substantial share of total income comprised by wages: 42 percent. Within the wage category, local wages were relatively dis-equalizing, while wages from employment outside the village were relatively equalizing. Non-farm family businesses contributed most to inequality compared to their share of income (29 percent compared to about 20 percent).

Taken together, these decompositions highlight two important sources of inequality, especially when we compare 2001 to 1987. First is the sharp decline of the relatively equalizing source of income from farming. Second is the relative increase in dis-equalizing income from non-farm family businesses, and the failure of non-farm labor markets to provide enough income opportunities for low-income 
households to offset the collapse of agricultural income. Past emphasis on the role of non-farm income as a source of inequality was only partially correct. Increasing agricultural incomes - at least in an equalizing way - are unlikely to improve overall income distribution, if for no other reason than agricultural incomes are only weakly associated with overall income, and they are also very low.

These results also underscore the important potential role of education in affecting the future trajectory of inequality. Success in family businesses, and in local and migration-based labor markets may be facilitated by higher levels of education. In the short run, as in urban areas, there may "excess returns" for those with more education, helping generate more inequality. In fact, as discussed by Benjamin, Brandt, Glewwe and Guo (2002), excess returns to education may be worsened even further in more remote areas with poorly developed markets. This is also potentially reflected in our previous contrast between the more remote inland versus coastal regions. Inequality of education, poorly developed offfarm opportunities, and low returns to farming do not bode well for the future. What is happening to the distribution of schooling?

Returning to Figure 6, we array the average years of schooling by age, sex, and year for rural areas (using the CHNS). As we saw for city-dwellers, there have been steady improvements in the level of education, reflected in all age categories. Most remarkable here are the relatively large gains made by women, significantly closing the gap with men, especially for the younger cohorts. The level of education is still lower, however, than in cities. To the extent that rural areas need economic development as much as the cities, it will be important that the urban-rural gap in schooling narrow over time.

Finally, in Figure 7 we explore the age-dimension of the income distribution. The general shape of the age-income profiles is similar in the rural sample to what we described for the urban sample: per capita income rises with age until age 60, then falls. Furthermore, the profiles have been moving upwards over time, reflecting general improvements in living standards. The most striking difference between the rural and urban pictures concerns the relative position of the elderly. In the countryside, the economic improvements experienced by the elderly (those over 60) are much smaller than for other age groups. The rural elderly are falling behind.

\subsection{Interim Conclusions and Apparent Themes}

Over the course of two and half decades of reform, China experienced a significant increase in inequality that is likely underestimated by the data we use. These increases are observed within both the urban and rural populations. In rural areas, this increase is tied to the dis-equalizing role of some forms of non-agricultural income, and laggard growth of farming income, especially beginning in the mid-1990s. In urban areas, on the other hand, a decline in the role of subsidies and entitlements, increasing wage inequality related to labor market and enterprise reform, and the effect of restructuring of SOE's on some 
cohorts and households through layoffs have all played a part in widening the income distribution. Corruption may have also played in role in distribution of wealth and welfare, but this is much more difficult to measure. Regional (spatial differences), although certainly present, are much less important than commonly believed for both urban and rural populations, as well as urban and rural combined. The same is true for differences between China's urban and rural areas.

This increase in inequality however must be seen in the context of rapidly rising incomes and improvements in welfare that literally pulled hundreds of millions out of poverty, especially in agriculture. Prior to the onset of reforms poverty in urban areas was very low, largely because of the severe urban bias in Chinese policy, and the fairly egalitarian distribution of incomes in the cities. Poverty does persist however-probably on the order of ten percent of the Chinese population or in excess of 120 million — and is largely a rural phenomenon. There is a need for more research in estimating and identifying the poor in both urban and rural areas. Probably the most obvious and feasible policy recommendation is to facilitate this research by improving access to nationally representative household survey data, as well as the implementation of household surveys designed to better measure income.

But there are obvious other areas of public policy that need to take account of rising inequality. First, a recurring theme in our research, as well as other chapters in this volume, is the important role played by education in both urban and rural areas. Probably no other single factor will be most closely tied to how the fruits of future growth are shared. Second, China will have to adopt and implement more features of a "social safety net," as even universal education will not be enough to generate a "povertyfree” income distribution. In the countryside, equally distributed land is unlikely to do the job, especially if returns to agriculture remain low. And finally, like most other countries, China will need to adopt a redistributive taxation system, both to support the social safety net, finance public goods, and allow the broader society to share in the obvious wealth being generated by the top part of the income distribution. Even with a richer understanding of the characteristics of the income distribution, the design and implementation of these and related types of policies will also provide a rich future research agenda. 


\subsection{References}

Behrman, Jere, Emily Hannum, and Meiyan Wang. 2005. "Human Capital in China," in China's Economic Transition: Origins, Mechanisms, and Consequences.

Benjamin, Dwayne and Loren Brandt. 1999. "Markets and Inequality in Rural China: Parallels with the Past." American Economic Review, 89:2, pp. 292-95.

Benjamin, Dwayne, Loren Brandt, and John Giles. 2005. "The Evolution of Income Inequality in Rural China." Economic Development and Cultural Change, 53:4, pp. 769-824.

Benjamin, Dwayne, Loren Brandt, Paul Glewwe, and Li Guo. 2002. "Markets, Human Capital, and Inequality: Evidence from China," in Inequality Around the World. Richard Freeman ed. London: Palgrave, pp. 87-127.

Brandt, Loren, Chang-Tai Hsieh, and Xiaodong Zhu. 2005. "Structural Transformation and Growth in China: 1978-2000," in China's Economic Transition: Origins, Mechanisms, and Consequences.

Brandt, Loren; and Carsten Holz. 2004. "Spatial Price Differences in China." Manuscript, University of Toronto.

Cai, Fang, Albert Park, and Yaohui Zhao. 2005. "The Chinese Labor Market," in China's Economic Transition: Origins, Mechanisms, and Consequences.

Deaton, Angus. 1997. The analysis of household surveys: A microeconometric approach to development policy. Baltimore and London: Johns Hopkins University Press for the World Bank.

Gustafsson, Bjorn and Li Shi. 2002. "Income inequality within and across counties in rural China 1988 and 1995." Journal of Development Economics, 69, pp. 179-204.

Hare, Denise. 1994. "Rural Nonagricultural Activities and their impact on the distribution of income: Evidence frlom farm households in southern China." China Economic Review, 5:1, pp. 59-82.

Kanbur, Ravi and Xiaobo Zhang. 1999. "Which Regional Inequality? The Evolution of Rural-Urban and Inland-Coastal Inequality in China, 1988 to 1995." Journal of Comparative Economics, 27:4, pp. 686-701.

Khan, Azizur Rahman and Carl Riskin. 1998. "Income and Inequality in China: Composition, Distribution and Growth of Household Income, 1988 to 1995." China Quarterly, 0:154, pp. 22153.

Khan, Azizur Rahman and Carl Riskin. 1999. "Income Distribution in Urban China during the Period of Economic Reform and Globalization." American Economic Review, 89:2, pp. 296-300.

Lardy, Nicholas. 1984. "Consumption and Living Standards in China, 1978-83." China Quarterly, 100, pp. 849-65. 
Meng, Xin. 2004. "Economic Restructuring and Income Inequality in Urban China." Review of Income and Wealth, 50:3, pp. 357-79.

Meng, Xin, Robert Gregory, and Youjuan Wang. 2004. "Poverty, inequality, and growth in urban China, 1986-2000." Manuscript, Australia National University.

Park, Albert, Xiaoqing Song, Junsen Zhang, and Yaohui Zhao. 2003. "The Growth of Wage Inequality in Urban China, 1988 to 1999." Unpublished Manuscript.

Ravallion, Martin and Shaohua Chen. 2004. "China's (Uneven) Progress Against Poverty." Manuscript, World Bank.

Rawski, Thomas. 1982. "The Simple Arithmetic of Chinese Income Distribution." Keizai Kenkyu, 33:1, pp. 12-26.

Shorrocks, Anthony F. 1982. "Decomposition by Factor Components." Econometrica, 50:1, pp. 193-211.

Shorrocks, Anthony F. 1983. "The Impact of Income Components on the Distribution of Family Incomes." Quarterly Journal of Economics, 98:2, pp. 311-26.

Vermeer, E.B. 1982. "Income Differentials in Rural China." China Quarterly, 89, pp. 1-33.

Yuen, Terence. 2000. Employment and Wage Dynamics: Estimating the Impact of Labour Market Institutions: Unpublished Dissertation, University of Toronto. 
Table 1

The Distribution of Household Per Capita Income

Selected Years

Urban and Rural Separately

\begin{tabular}{|c|c|c|c|c|}
\hline & 1987 & 1991 & 1995 & 2001 \\
\hline \multicolumn{5}{|c|}{ Urban (NBS) } \\
\hline Mean Income & 1533 & 1742 & 2385 & 3411 \\
\hline Gini & 0.22 & 0.25 & 0.30 & 0.34 \\
\hline Gini (Spatially deflated) & 0.20 & 0.22 & 0.28 & 0.33 \\
\hline Theil & 0.08 & 0.10 & 0.16 & 0.20 \\
\hline Atkinson (0.5) & 0.04 & 0.05 & 0.07 & 0.10 \\
\hline Atkinson (1) & 0.08 & 0.10 & 0.14 & 0.18 \\
\hline Atkinson (2) & 0.15 & 0.18 & 0.25 & 0.31 \\
\hline $90 / 10$ & 2.64 & 2.97 & 3.90 & 4.77 \\
\hline Below $0.5 \times 1987$ Median & 0.04 & 0.05 & 0.02 & 0.01 \\
\hline \multicolumn{5}{|l|}{ Consumption-based measures: } \\
\hline Mean per capita consumption & 1346 & 1491 & 1994 & 2702 \\
\hline Gini & 0.24 & 0.27 & 0.32 & 0.35 \\
\hline \multicolumn{5}{|c|}{ Rural (RCRE) } \\
\hline Mean Income & 920 & 877 & 1225 & 1244 \\
\hline Gini & 0.32 & 0.33 & 0.33 & 0.37 \\
\hline Gini (Spatially deflated) & 0.29 & 0.30 & 0.30 & 0.34 \\
\hline Theil & 0.19 & 0.22 & 0.21 & 0.27 \\
\hline Atkinson (0.5) & 0.08 & 0.09 & 0.09 & 0.12 \\
\hline Atkinson (1) & 0.16 & 0.17 & 0.17 & 0.21 \\
\hline Atkinson (2) & 0.28 & 0.32 & 0.33 & 0.43 \\
\hline $90 / 10$ & 4.06 & 3.98 & 3.93 & 4.99 \\
\hline Below $0.5 \times 1987$ Median & 0.16 & 0.19 & 0.07 & 0.11 \\
\hline \multicolumn{5}{|l|}{ Consumption-based measures: } \\
\hline Mean per capita consumption & 652 & 635 & 864 & 826 \\
\hline Gini & 0.25 & 0.27 & 0.27 & 0.33 \\
\hline
\end{tabular}

Notes: (1) All calculations are based on real per capita income, expressed in constant 1990 yuan; (2) The "Spatially Deflated” Gini calculation is based on further adjustments for geographic differences in cost-of-living as described in Brandt and Holz (2004); (3) “90/10" is the ratio of the $90^{\text {th }}$ to the $10^{\text {th }}$ percentiles of the income distribution; (4) "Below $0.5 \times 1987$ Median" is the proportion of individuals with per capita incomes below a constant benchmark, namely one-half the median 1987 per capita income. 
Table 2

The Distribution of Household Per Capita Income

Selected Years, CHNS

Urban and Rural Separately

\begin{tabular}{|c|c|c|c|c|}
\hline & 1991 & 1993 & 1997 & 2000 \\
\hline \multicolumn{5}{|c|}{ Urban } \\
\hline Mean Income & 1484 & 1651 & 1982 & 2532 \\
\hline Gini & 0.29 & 0.35 & 0.35 & 0.38 \\
\hline \multicolumn{5}{|l|}{ Theil } \\
\hline Atkinson (0.5) & 0.07 & 0.10 & 0.11 & 0.13 \\
\hline Atkinson (1) & 0.15 & 0.22 & 0.23 & 0.27 \\
\hline Atkinson (2) & 0.40 & 0.50 & 0.59 & 0.62 \\
\hline $90 / 10$ & 4.40 & 6.50 & 6.32 & 8.24 \\
\hline \multicolumn{5}{|l|}{ Below $0.5 \times 1987$ Median } \\
\hline \multicolumn{5}{|c|}{ Rural } \\
\hline Mean Income & 917 & 984 & 1344 & 1623 \\
\hline Gini & 0.39 & 0.43 & 0.41 & 0.46 \\
\hline Theil & 0.26 & 0.32 & 0.28 & 0.36 \\
\hline Atkinson (0.5) & 0.13 & 0.15 & 0.14 & 0.18 \\
\hline Atkinson (1) & 0.25 & 0.31 & 0.28 & 0.36 \\
\hline Atkinson (2) & 0.31 & 0.68 & 0.66 & 0.77 \\
\hline $90 / 10$ & 7.25 & 8.78 & 8.76 & 11.65 \\
\hline Below $0.5 \times 1987$ Median & 0.21 & 0.22 & 0.13 & 0.13 \\
\hline
\end{tabular}

Notes: (1) All calculations are based on real per capita income, expressed in constant 1990 yuan; (2) "90/10" is the ratio of the $90^{\text {th }}$ to the $10^{\text {th }}$ percentiles of the income distribution; (4) “ Below 0.5× 1987 Median” is the proportion of individuals with per capita incomes below a constant benchmark, namely one-half the median 1987 per capita income. 
Table 3

Spatial Variation of Incomes, Selected years

Urban and Rural Separately

Various Data Sets

\begin{tabular}{|c|c|c|c|c|}
\hline \multirow[b]{2}{*}{ Urban (NBS) } & 1987 & 1991 & 1995 & 2001 \\
\hline & \multirow{3}{*}{0.26} & \multirow{3}{*}{0.30} & & \\
\hline Province & & & 0.37 & 0.28 \\
\hline City & & & 0.48 & 0.39 \\
\hline Province (Spatially deflated) & \multirow[t]{2}{*}{0.17} & \multirow[t]{2}{*}{0.17} & 0.29 & 0.13 \\
\hline City (Spatially deflated) & & & 0.34 & 0.27 \\
\hline \multicolumn{5}{|l|}{ Rural (RCRE) } \\
\hline Province & 0.24 & 0.22 & 0.18 & 0.19 \\
\hline Village & 0.50 & 0.47 & 0.41 & 0.43 \\
\hline Province (Spatially deflated) & 0.13 & 0.11 & 0.09 & 0.11 \\
\hline \multirow[t]{3}{*}{ Village (Spatially deflated) } & 0.43 & 0.39 & 0.35 & 0.33 \\
\hline & \multicolumn{4}{|c|}{ CHNS-Based } \\
\hline & 1991 & 1993 & 1997 & 2000 \\
\hline \multicolumn{5}{|l|}{ Urban (CHNS) } \\
\hline Province & 0.04 & 0.05 & 0.06 & 0.02 \\
\hline City & 0.29 & 0.29 & 0.25 & 0.13 \\
\hline \multicolumn{5}{|l|}{ Rural (CHNS) } \\
\hline Province & 0.06 & 0.06 & 0.06 & 0.05 \\
\hline Village & 0.24 & 0.30 & 0.22 & 0.21 \\
\hline
\end{tabular}

Notes: (1) This table reports the proportion of total variation of log per capita income explained by a set of location indicators. This is calculated as the R-squared from a regression of "In $y$ ” on a set of dummy variables for province, city, or cluster, depending on the level of spatial analysis. (2) The "spatially deflated" series refer to incomes adjusted for provincial differences in the cost of living, as calculated by Brandt and Holz (2004). 
Table 4

Inequality for Combined Urban and Rural Samples CHNS Data

\begin{tabular}{|c|c|c|c|c|}
\hline & 1991 & 1993 & 1997 & 2000 \\
\hline \multicolumn{5}{|l|}{ Pooled Distributional Characteristics } \\
\hline Mean Per Capita Income & 1121 & 1194 & 1560 & 1912 \\
\hline Gini Coefficient & 0.37 & 0.42 & 0.40 & 0.44 \\
\hline Atkinson (0.5) & 0.12 & 0.15 & 0.13 & 0.17 \\
\hline Atkinson (1) & 0.24 & 0.30 & 0.27 & 0.34 \\
\hline Atkinson (2) & 0.51 & 0.67 & 0.66 & 0.76 \\
\hline 90/10 Ratio & 6.93 & 8.82 & 8.49 & 11.04 \\
\hline \multicolumn{5}{|l|}{ Spatial Decompositions } \\
\hline Province Only & 0.05 & 0.04 & 0.05 & 0.06 \\
\hline Province plus Urban-Rural (interactions) & 0.17 & 0.14 & 0.12 & 0.14 \\
\hline City or Village (Cluster) & 0.31 & 0.36 & 0.28 & 0.17 \\
\hline
\end{tabular}

Notes: (1) This table reports mean incomes and inequality measures for a combined sample of urban and rural households, where adjustment has been made for spatial differences in the cost of living, including urban-rural differences in prices (from Brandt and Holz, 2004); (2) All figures are reported based on the spatially deflated, constant 1990 yuan; (3) The spatial decompositions are the same as described in Tables 8 and 9. (4) "Province plus Urban-Rural” means province interacted with a rural/urban indicator (which does not permit spatial differences within the urban or rural sectors within a province). 
Table 5

The Sensitivity of Urban-Rural Distinctions to the Definition of "Rural" Mean Per Capita Incomes and Growth, CHNS

\begin{tabular}{lccccc}
\hline & $\mathbf{1 9 9 1}$ & $\mathbf{1 9 9 3}$ & $\mathbf{1 9 9 7}$ & $\mathbf{2 0 0 0}$ & Growth \\
\cline { 3 - 5 } Fixed Definition of Rural & & & & & \\
\cline { 1 - 4 } Rural Mean Income & 917 & 984 & 1343 & 1623 & 0.063 \\
Urban Mean Income & 1484 & 1651 & 1982 & 2532 & 0.059 \\
Urban/Rural Ratio & 1.62 & 1.68 & 1.48 & 1.56 & \\
Evolving Definition of Rural & & & & & \\
\cline { 1 - 3 } Rural Mean Income & 772 & 766 & 1042 & 1108 & 0.040 \\
Urban Mean Income & 1391 & 1474 & 1798 & 2106 & 0.046 \\
Urban/Rural Ratio & 1.80 & 1.92 & 1.73 & 1.90 & \\
\hline
\end{tabular}

Notes: (1) This table shows mean per capita incomes expressed in constant 1990 yuan, for two types of rural definition. (2) The first definition of urban-rural is based on the CHNS sampling definition, where "rural" includes "purely" rural and "suburban" households, approximately corresponding to rural registered households. This definition is fixed for the entire period, so that a 1991 rural household (cluster) remains rural in 2000. (3) The second definition is based on economic structure, and evolves with economic development. Clusters are defined as rural if fifty percent or more of households earn fifty percent or more of their income from farming (i.e., most of the households are farmers). This definition is re-calculated each survey, so clusters can evolve from rural to urban classification. (4) "Growth" is defined as the implied annual compounded rate from 1991 through 2000. 
Table 6

Combined Urban and Rural Inequality

Exploring the Interaction with Geography (Inland versus Coastal Provinces)

(CHNS)

\begin{tabular}{|c|c|c|c|c|}
\hline & 1991 & 1993 & 1997 & 2000 \\
\hline & \multicolumn{4}{|c|}{ Distributional Characteristics } \\
\hline \multicolumn{5}{|l|}{ Coastal regions } \\
\hline Mean Per Capita Income (Combined) & 1167 & 1316 & 1746 & 2215 \\
\hline Mean, Urban Separately & 1580 & 1792 & 2153 & 2725 \\
\hline Mean, Rural Separately & 991 & 1150 & 1620 & 2065 \\
\hline Gini Coefficient (Combined) & 0.35 & 0.39 & 0.37 & 0.39 \\
\hline Gini, Urban Separately & 0.26 & 0.34 & 0.35 & 0.37 \\
\hline Gini, Rural Separately & 0.38 & 0.40 & 0.38 & 0.39 \\
\hline \multicolumn{5}{|l|}{ Interior regions } \\
\hline Mean Per Capita Income (Combined) & 1078 & 1086 & 1433 & 1652 \\
\hline Mean, Urban Separately & 1352 & 1473 & 1862 & 2338 \\
\hline Mean, Rural Separately & 858 & 850 & 1152 & 1265 \\
\hline Gini Coefficient (Combined) & 0.39 & 0.45 & 0.41 & 0.48 \\
\hline Gini, Urban Separately & 0.31 & 0.37 & 0.35 & 0.39 \\
\hline \multirow[t]{2}{*}{ Gini, Rural Separately } & 0.40 & 0.45 & 0.42 & 0.49 \\
\hline & \multicolumn{4}{|c|}{ Spatial Decompositions } \\
\hline \multicolumn{5}{|l|}{ Coastal regions } \\
\hline Province & 0.04 & 0.01 & 0.02 & 0.02 \\
\hline Province plus Urban-Rural & 0.14 & 0.10 & 0.06 & 0.06 \\
\hline City/Village & 0.46 & 0.43 & 0.29 & 0.24 \\
\hline \multicolumn{5}{|l|}{ Interior regions } \\
\hline Province & 0.04 & 0.04 & 0.03 & 0.02 \\
\hline Province plus Urban-Rural & 0.15 & 0.13 & 0.10 & 0.13 \\
\hline City/Village & 0.35 & 0.33 & 0.26 & 0.30 \\
\hline
\end{tabular}

Notes: (1) This table reports mean incomes and inequality measures for a combined sample of urban and rural households, where adjustment has been made for spatial differences in the cost of living, including urban-rural differences in prices (from Brandt and Holz, 2004); (2) All figures are reported based on the spatially deflated, constant 1990 yuan; (3) The spatial decompositions are the same as described in Tables 8 and 9. "Province plus Urban-Rural” means province interacted with a rural/urban indicator (which does not permit spatial differences within the urban or rural sectors within a province) 
Table 7

Spatial Income Differences Across Regions

\begin{tabular}{|c|c|c|c|c|c|c|}
\hline \multirow[b]{2}{*}{ Year } & \multicolumn{3}{|c|}{ Mean Income } & \multicolumn{3}{|c|}{ Gini Coefficients } \\
\hline & Rural & Urban & Ratio & Rural & Urban & Combined \\
\hline \multicolumn{7}{|c|}{ Inland Provinces } \\
\hline 1985 & 744 & 1225 & 1.65 & 0.092 & 0.087 & 0.147 \\
\hline 1988 & 743 & 1357 & 1.82 & 0.092 & 0.083 & 0.169 \\
\hline 1991 & 741 & 1519 & 2.05 & 0.081 & 0.090 & 0.197 \\
\hline 1994 & 833 & 1911 & 2.29 & 0.107 & 0.103 & 0.235 \\
\hline 1997 & 1102 & 2122 & 1.92 & 0.087 & 0.111 & 0.202 \\
\hline 2000 & 1222 & 2672 & 2.19 & 0.085 & 0.109 & 0.234 \\
\hline \multicolumn{7}{|c|}{ Coastal Provinces } \\
\hline 1985 & 857 & 1295 & 1.51 & 0.065 & 0.087 & 0.128 \\
\hline 1988 & 953 & 1499 & 1.57 & 0.059 & 0.110 & 0.151 \\
\hline 1991 & 993 & 1717 & 1.73 & 0.054 & 0.099 & 0.164 \\
\hline 1994 & 1206 & 2268 & 1.88 & 0.095 & 0.114 & 0.196 \\
\hline 1997 & 1647 & 2566 & 1.56 & 0.082 & 0.100 & 0.153 \\
\hline 2000 & 1852 & 3140 & 1.70 & 0.087 & 0.102 & 0.175 \\
\hline
\end{tabular}

Notes: (1) This table shows the "simulated" Pooled Gini coefficient for inland and coastal China, in which each individual in a province is attributed the mean per capita income for that province. This effectively sets withinprovince inequality to zero for urban and rural China respectively. (2) The urban and rural Gini's are based on spatially deflated per capita incomes, accounting for cross-province price differences, while the pooled Gini also spatially deflates with account for different prices in urban and rural areas. (3) For reference, we also show the ratio of urban to rural spatially deflated mean incomes. (4) Source: Authors' calculations using NBS Yearbooks. 
Table 8

Composition of Income and Inequality Decompositions by Source

Sample "End-points"

Urban and Rural Separately

\begin{tabular}{|c|c|c|c|c|c|c|}
\hline & \multicolumn{6}{|c|}{ Urban (NBS) } \\
\hline & \multicolumn{3}{|c|}{1987} & \multicolumn{3}{|c|}{2001} \\
\hline & $\mathbf{p}>\mathbf{0}$ & Share & Shorrocks & $\mathbf{p}>\mathbf{0}$ & Share & Shorrocks \\
\hline Wage Income & 0.98 & 0.86 & 0.66 & 0.87 & 0.68 & 0.72 \\
\hline Family Business & 0.02 & 0.01 & 0.03 & 0.15 & 0.05 & 0.01 \\
\hline Pensions & 0.20 & 0.07 & 0.12 & 0.33 & 0.15 & 0.11 \\
\hline Family Transfers & 0.34 & 0.02 & 0.10 & 0.35 & 0.02 & 0.03 \\
\hline \multirow[t]{4}{*}{ Other } & 0.96 & 0.03 & 0.09 & 0.67 & 0.07 & 0.13 \\
\hline & \multicolumn{6}{|c|}{ Urban (CHNS) } \\
\hline & \multicolumn{3}{|c|}{1991} & \multicolumn{3}{|c|}{2000} \\
\hline & $\mathbf{p}>\mathbf{0}$ & Share & Shorrocks & $\mathbf{p}>\mathbf{0}$ & Share & Shorrocks \\
\hline Wage Income & 0.77 & 0.46 & 0.32 & 0.64 & 0.52 & 0.46 \\
\hline Family Business & 0.15 & 0.07 & 0.35 & 0.17 & 0.10 & 0.37 \\
\hline Subsidies & 0.95 & 0.28 & 0.19 & 0.59 & 0.07 & 0.02 \\
\hline Farming & 0.18 & 0.07 & 0.00 & 0.06 & 0.02 & 0.01 \\
\hline Other & 0.55 & 0.13 & 0.15 & 0.65 & 0.28 & 0.15 \\
\hline \multirow[t]{4}{*}{ (of which is Pensions) } & 0.30 & 0.09 & & 0.35 & 0.17 & \\
\hline & \multicolumn{6}{|c|}{ Rural (RCRE) } \\
\hline & \multicolumn{3}{|c|}{1987} & \multicolumn{3}{|c|}{2001} \\
\hline & $\mathbf{p}>\mathbf{0}$ & Share & Shorrocks & $\mathbf{p}>\mathbf{0}$ & Share & Shorrocks \\
\hline Wage Income & 0.71 & 0.25 & 0.37 & 0.71 & 0.42 & 0.44 \\
\hline Family Business & 0.62 & 0.16 & 0.34 & 0.47 & 0.20 & 0.29 \\
\hline Agricultural Income & 0.98 & 0.40 & 0.13 & 0.92 & 0.21 & 0.06 \\
\hline Agricultural Sidelines & 0.96 & 0.13 & 0.07 & 0.73 & 0.10 & 0.18 \\
\hline Family Transfers & 0.52 & 0.05 & 0.08 & 0.46 & 0.05 & 0.03 \\
\hline Government Transfers & 0.65 & 0.01 & 0.00 & 0.71 & 0.01 & 0.00 \\
\hline Other & 0.14 & 0.01 & 0.01 & 0.09 & 0.01 & 0.01 \\
\hline \multicolumn{7}{|c|}{$\begin{array}{l}\text { Notes: (1) This table reports the composition of income, and the associated Shorrocks decompositions for urban and } \\
\text { rural per capita household income; }(2) \text { "p }>0 \text { " is the proportion of households (individuals) reporting positive (non- } \\
\text { zero) income from the given source; (3) The "Share" is the proportion (share) of total income earned in the specified } \\
\text { category; (4) The Shorrocks decompositions report the proportion of total inequality that can be attributed to } \\
\text { inequality of that particular income source. }\end{array}$} \\
\hline
\end{tabular}


Table 9

The Distribution of Wage Earnings Urban, CHNS

\begin{tabular}{lcccc}
\hline & $\mathbf{1 9 9 1}$ & $\mathbf{1 9 9 3}$ & $\mathbf{1 9 9 7}$ & $\mathbf{2 0 0 0}$ \\
\hline & \multicolumn{3}{c}{ All Households } \\
Gini & 0.49 & 0.56 & 0.57 & 0.67 \\
Theil E & 0.46 & 0.61 & 0.64 & 0.91 \\
Coefficient of Variation & 0.94 & 1.25 & 1.26 & \\
& & & & \\
Proportion of All Households & & Households with Positive Earnings & 0.58 \\
Gini & 0.75 & 0.72 & 0.66 & 0.42 \\
Theil E & 0.32 & 0.39 & 0.23 & 0.36 \\
Coefficient of Variation & 0.17 & 0.28 & 0.81 & 1.13 \\
\hline
\end{tabular}

Decomposition of Variance of Log Earnings: Hours versus "Wages” (Among those with positive Earnings)

\begin{tabular}{lcccccccc}
\hline & Var & \% & Var & \% & Var & \% & Var & \% \\
\hline Var (log wage earnings) & 0.416 & 100 & 0.569 & 100 & 0.457 & 100 & 0.663 & 100 \\
Var (log months worked) & 0.221 & 53.1 & 0.253 & 44.5 & 0.18 & 39.4 & 0.233 & 35.1 \\
Var (log monthly wage) & 0.163 & 39.2 & 0.297 & 52.2 & 0.261 & 57.1 & 0.365 & 55.1 \\
Covariance (hours, wages) & 0.032 & 7.7 & 0.016 & 2.8 & 0.016 & 3.5 & 0.065 & 9.8 \\
\hline
\end{tabular}

Notes: (1) This table uses the CHNS data to describe inequality of wage income in urban areas; (2) All nominal figures are expressed in constant 1990 yuan; (3) The top two panels report various measures of wage-income (earnings) inequality, including or excluding households with "zeroes” (unconditional, or conditional, on positive earnings); (4) The bottom panel reports the total variance of log earnings, decomposed into constituent log months worked and log average monthly wages, as well as the covariance between log months worked and log monthly wages ("Covariance (hours, wages)"). (5) The decomposition is expressed in levels, as well as the percentage of total variation explained “\%”) 
Table 10

The Distribution of Farm Land

Land Inequality and Spatial Variation

Rural, RCRE

\begin{tabular}{|c|c|c|c|c|}
\hline & 1987 & 1991 & 1995 & 2002 \\
\hline \multicolumn{5}{|c|}{ Land Inequality } \\
\hline Gini & 0.37 & 0.37 & 0.39 & 0.48 \\
\hline 90/10 Ratio & 5.43 & 5.94 & 7.50 & 25.60 \\
\hline \multicolumn{5}{|c|}{ Spatial Variation } \\
\hline Province & 0.34 & 0.35 & 0.32 & 0.31 \\
\hline Village & 0.73 & 0.71 & 0.62 & 0.70 \\
\hline
\end{tabular}

Notes: (1) Land is defined as total per capita land managed by the household. This includes village-allocated land, plus land contracted in, less land contracted out; (2) Spatial variation is the proportion of total variation of log per capita land explained by a set of location indicators. This is calculated as the R-squared from a regression of "In per capita land" on a set of dummy variables for province or village, depending on the level of spatial analysis. 
Figure 1: The Evolution of Mean Per-Capita Household Income, Selected Years

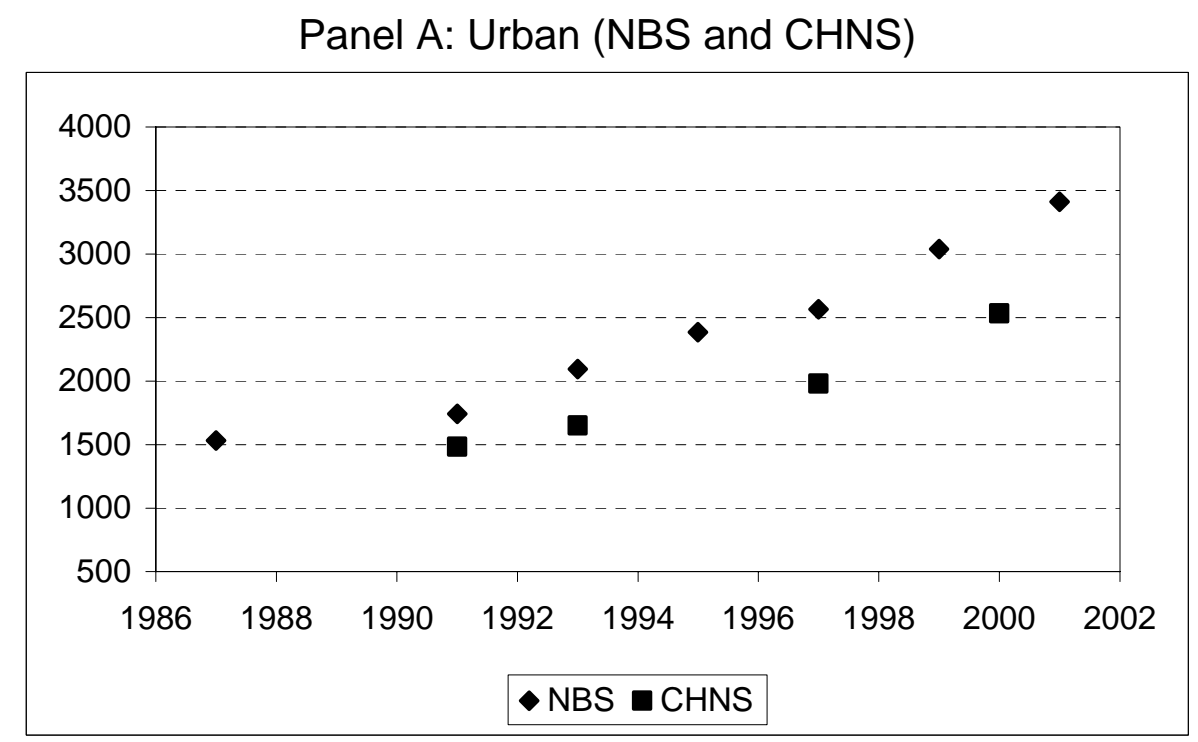

Implied Annual Growth Rate (NBS): $5.7 \%$

Implied Annual Growth Rate (CHNS): 5.9\%

Panel B: Rural (NBS and CHNS)

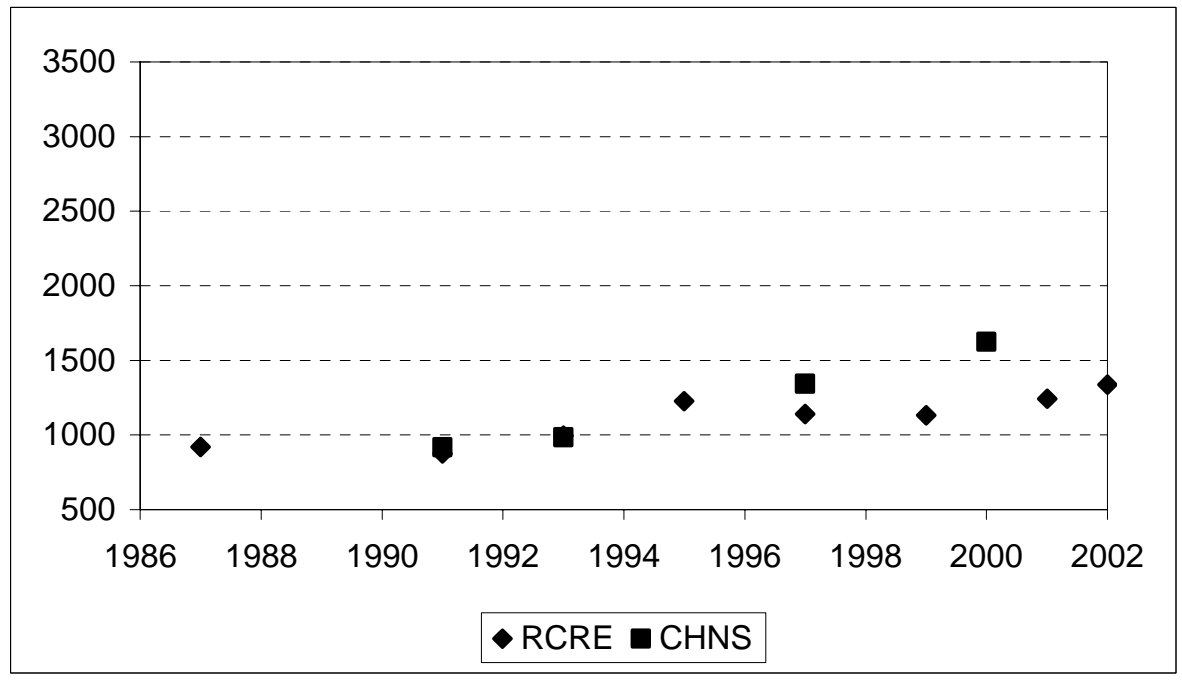

Implied Annual Growth Rate (RCRE): 2.0\% Implied Annual Growth Rate (CHNS): 6.3\%

Notes: (1) All calculations based on real per capita income, expressed in constant 1990 yuan. (2) The "Implied Growth Rate” is the average annual continuously compounded growth rate between the beginning and the end of the sample period. For Urban NBS, the endpoints are 1987 and 2001; for Rural RCRE, the endpoints are 1987 and 2002; and for the CHNS, the endpoints are 1991 and 2000. (3) See Tables 1 and 2 for further details. 
Figure 2: The Evolution of Inequality (the Gini Coefficient), Selected Years

\section{Panel A: Urban (NBS and CHNS)}

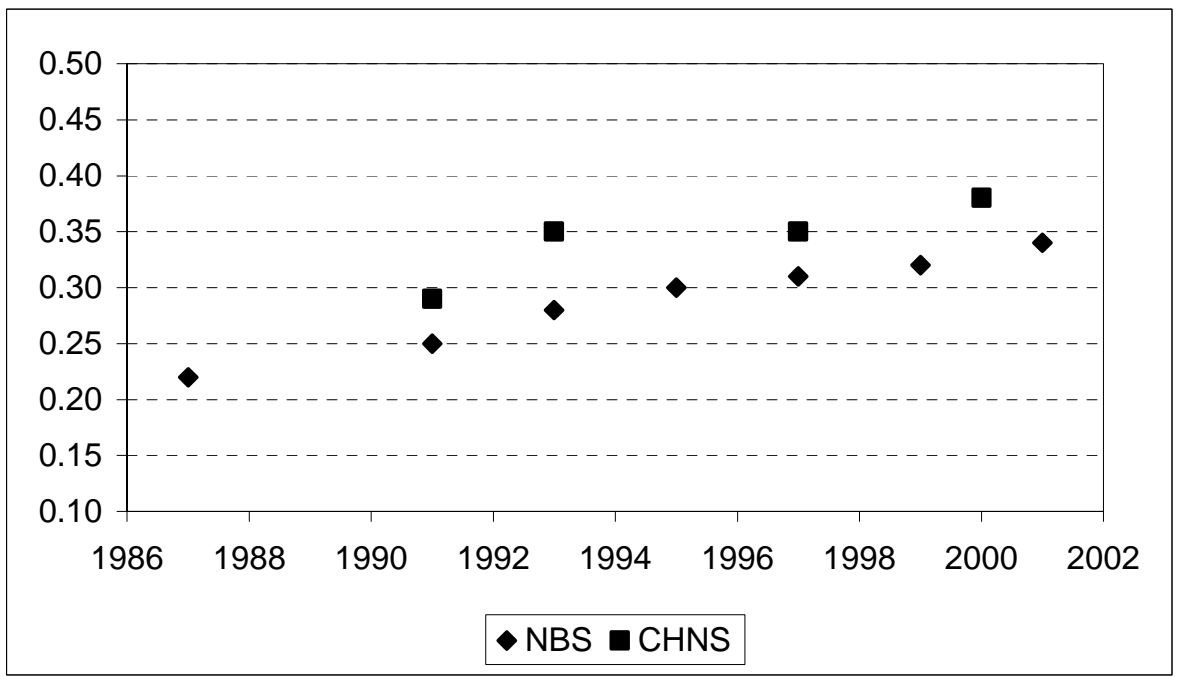

Panel B: Rural (RCRE and CHNS)

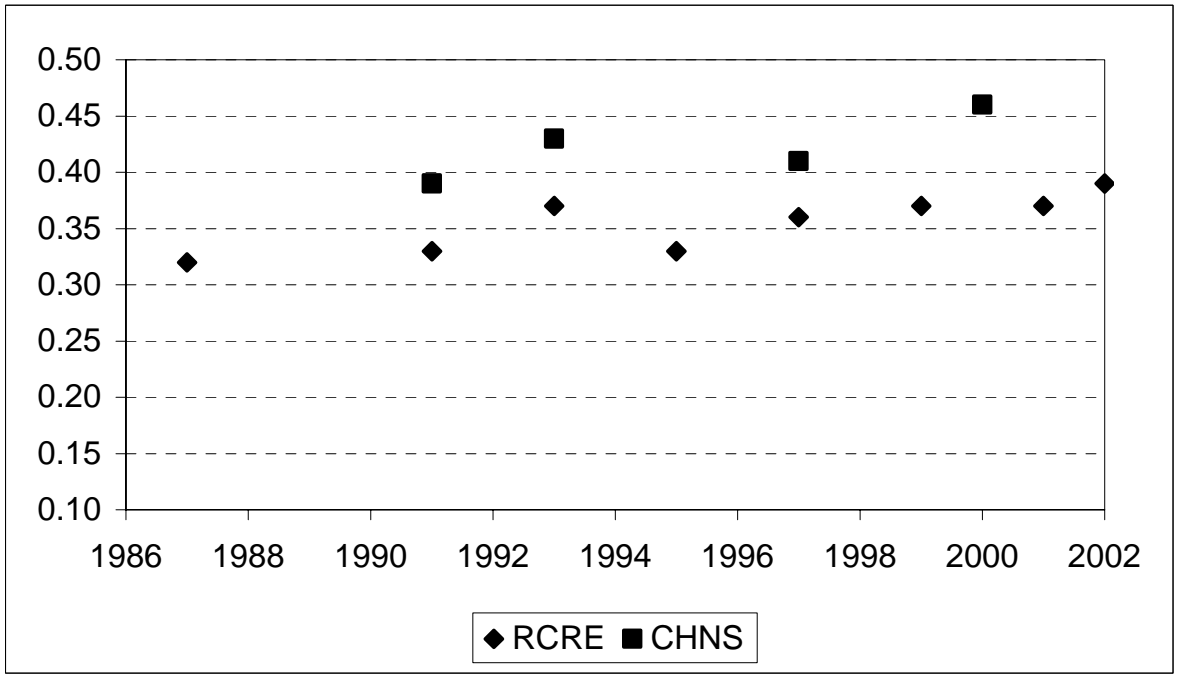

Notes: (1) All calculations are based on real per capita household income, expressed in constant 1990 yuan. (2) See notes to Tables 1 and 2 for further details. 
Figure 3: Lorenz Curves, Urban and Rural Incomes

Urban
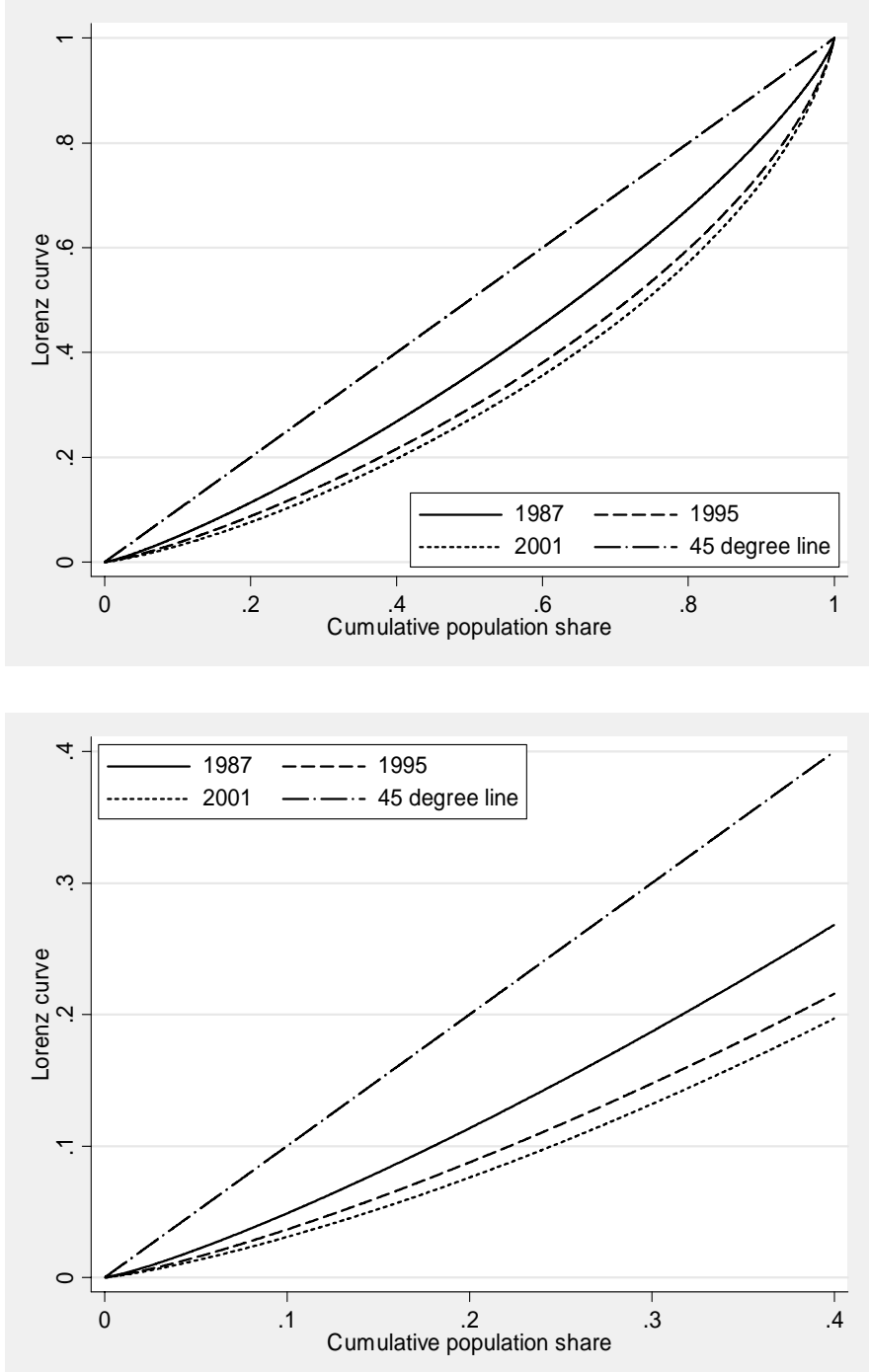

Rural
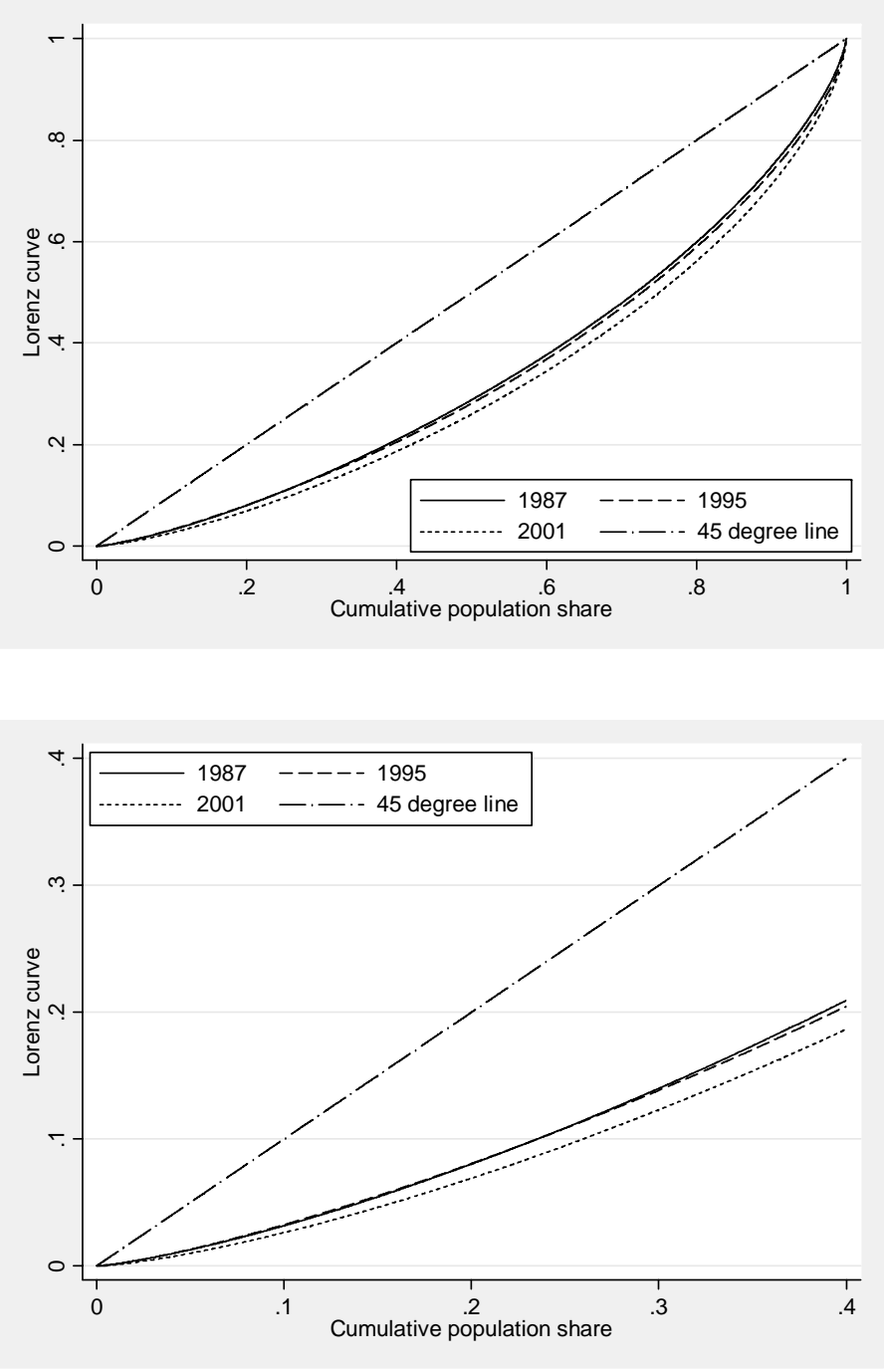

Notes: The Lorenz curves are based on the urban (NSB) and rural (RCRE) data described in Table 1. All calculations are based on spatially-undeflated, constant 1990 yuan. 
Figure 4: Cumulative Distribution Functions, Urban and Rural Incomes

\section{Urban}
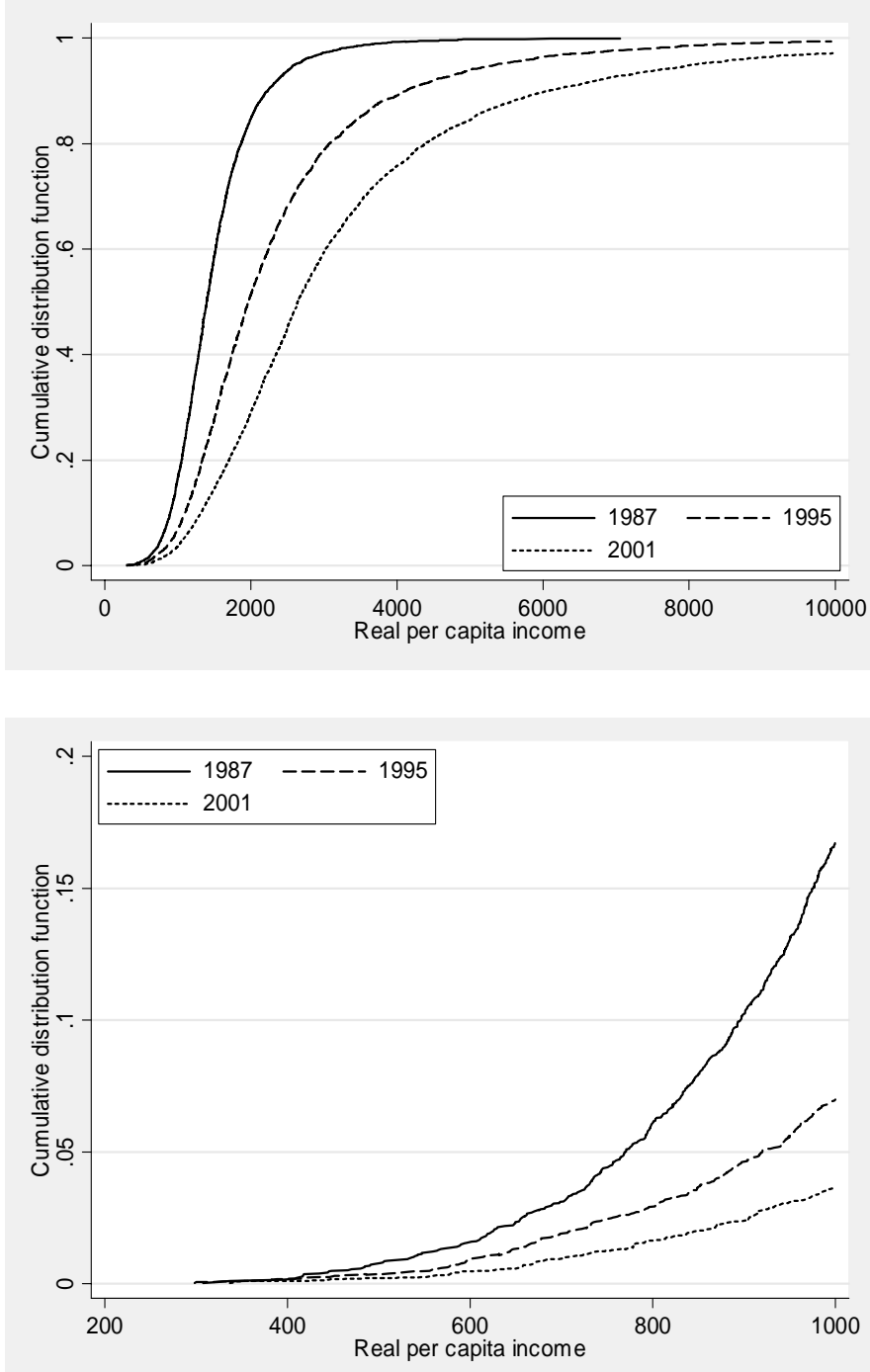

\section{Rural}
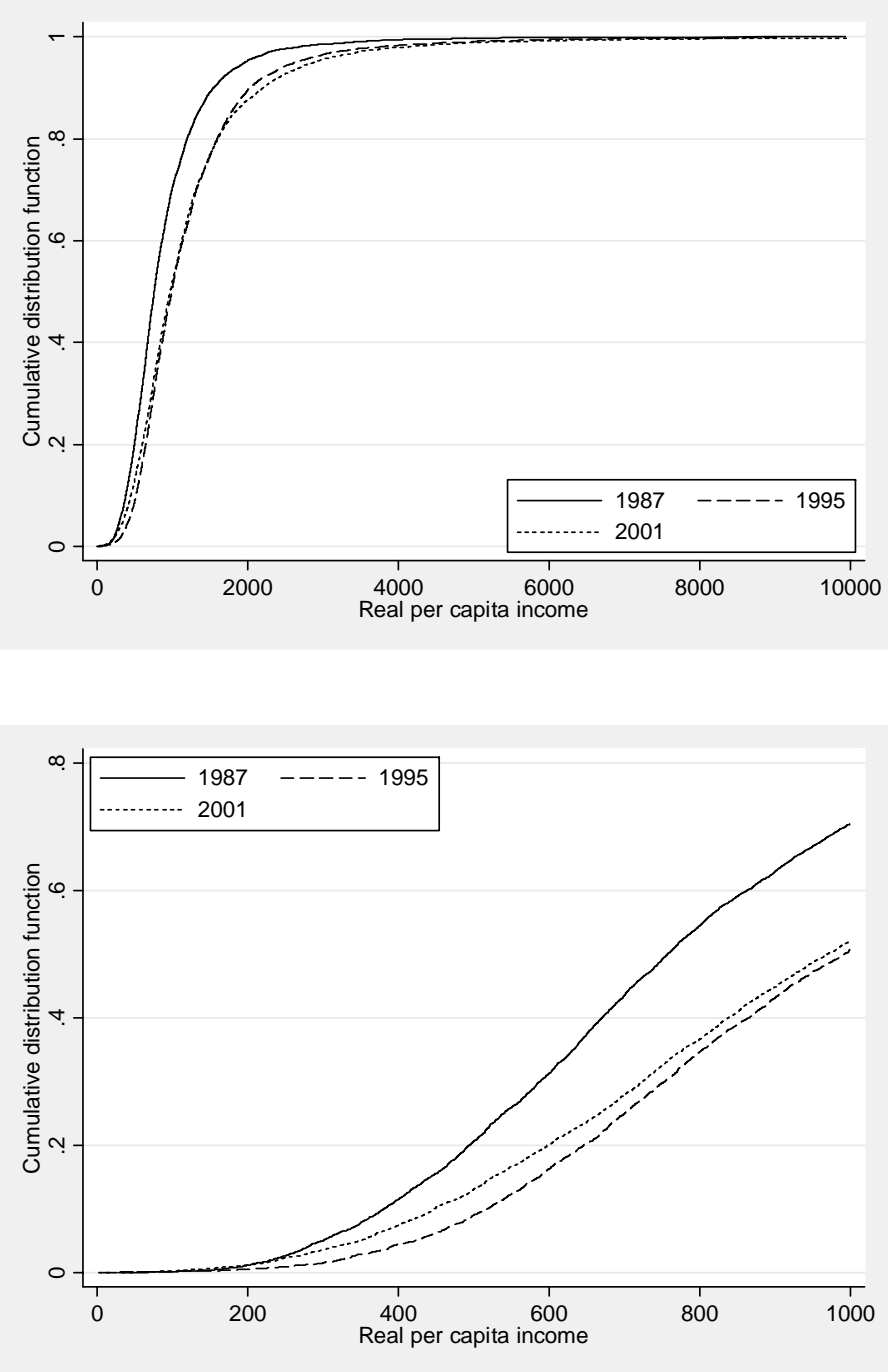

Notes: The Cumulative Distribution Functions (CDF's) are based on the urban (NSB) and rural (RCRE) data described in Table 1. All calculations are based on spatiallyundeflated, constant 1990 yuan. 
Figure 5: Wage-Employment By Age and Sex, Urban

Panel A: Men

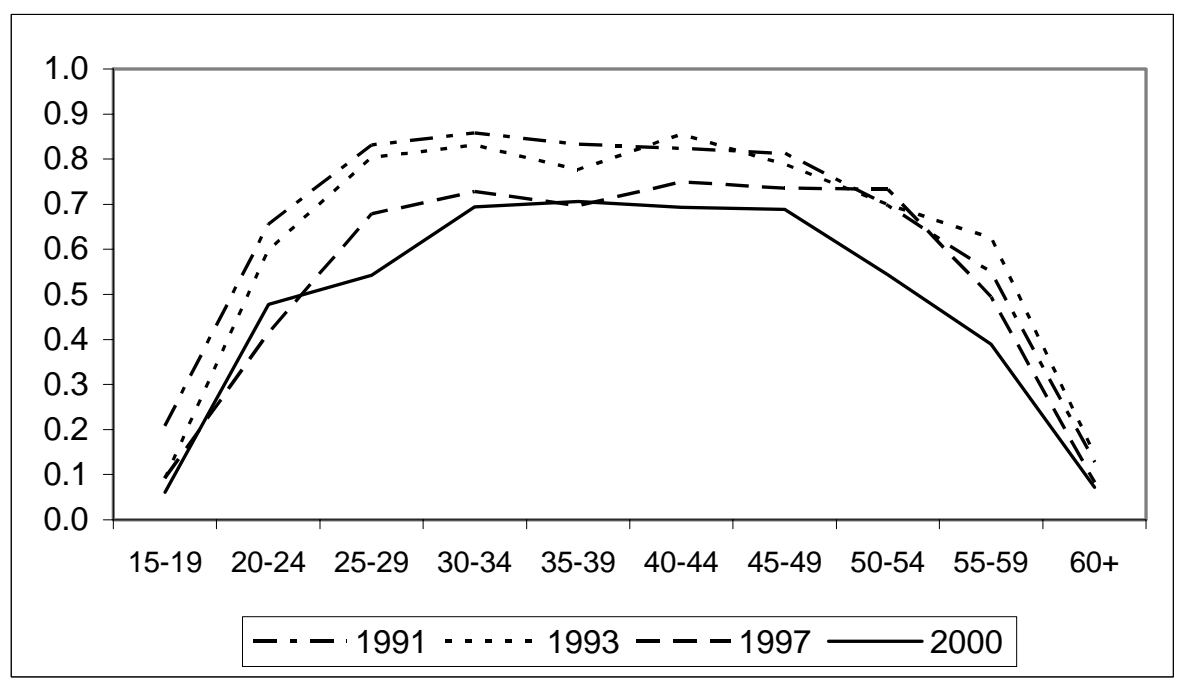

Panel B: Women

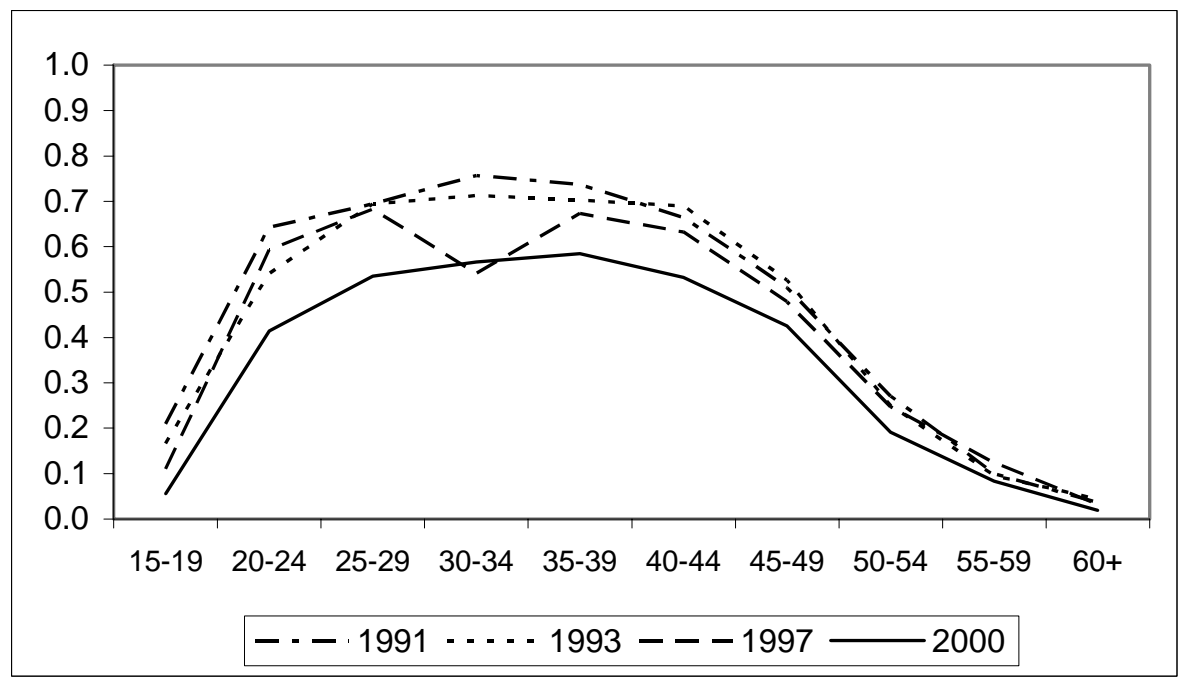

Source: Authors calculations based on the CHNS 


\section{Figure 6: Education by Age, Sex, and Year (Urban and Rural, Separately)}

Urban Men

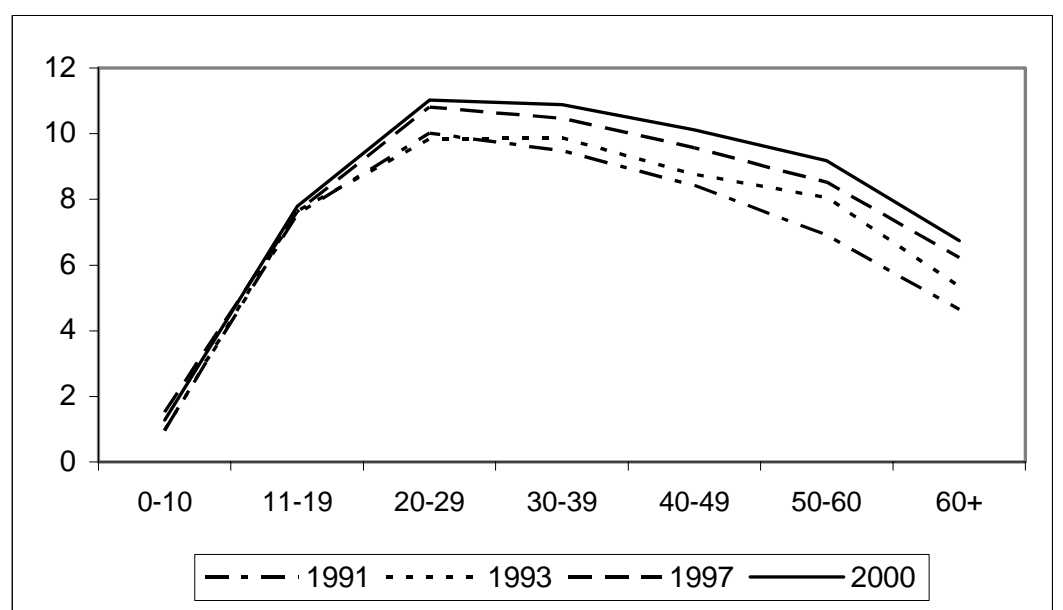

Rural Men

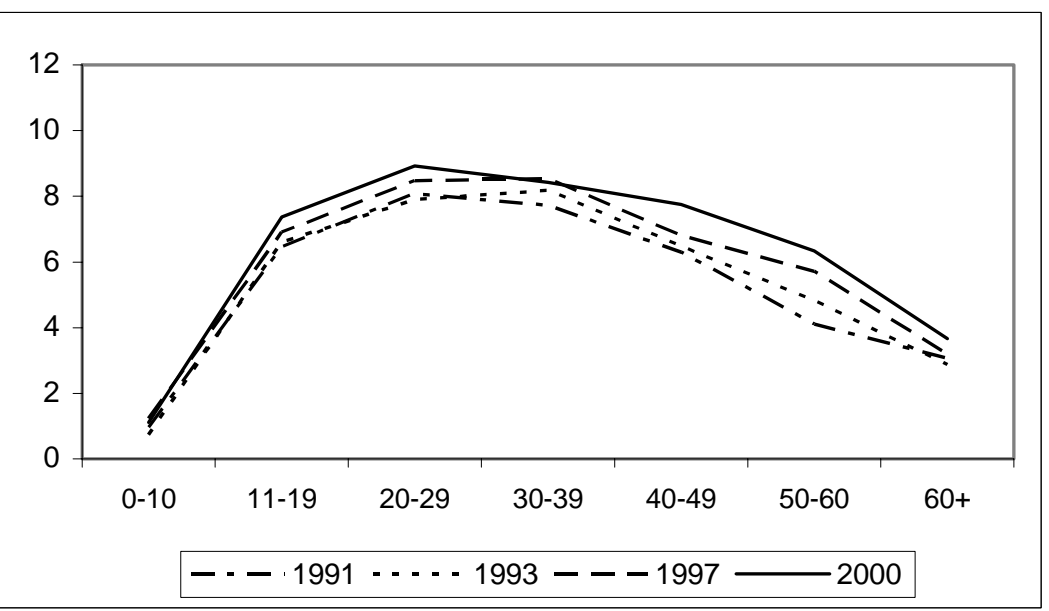

Urban Women

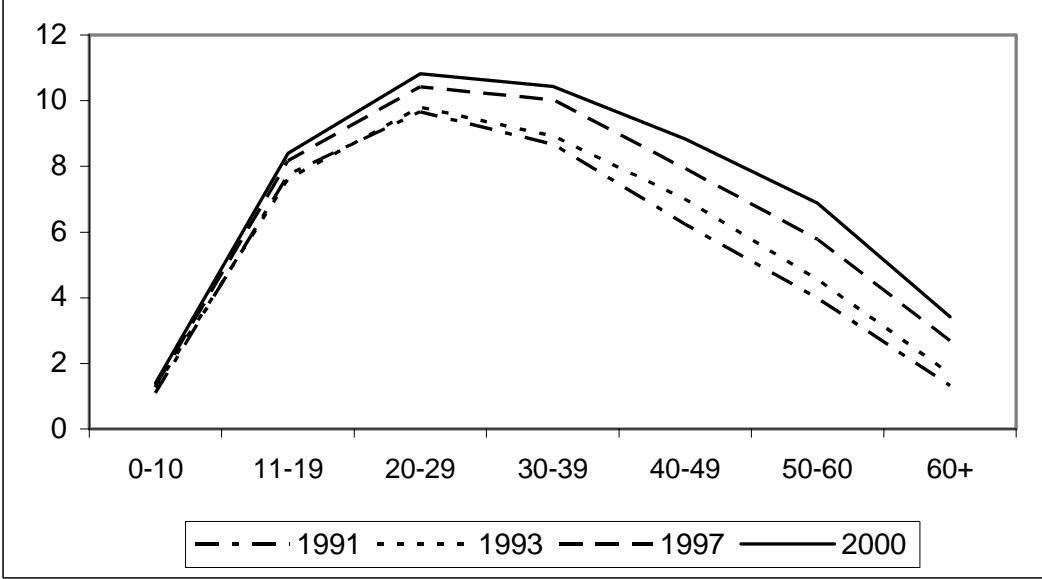

Rural Women

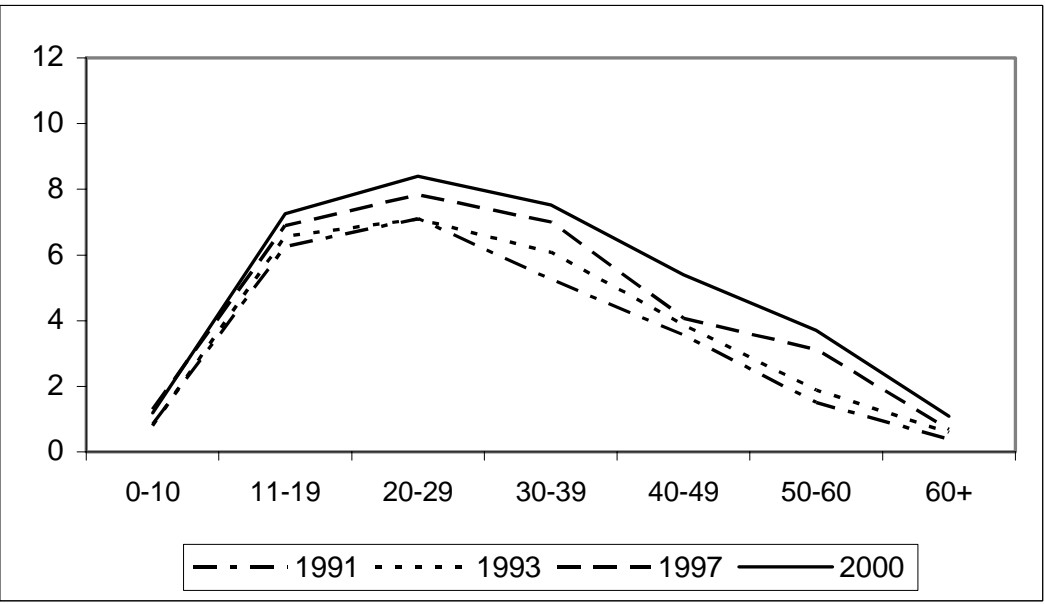

Source: Authors calculations based on the CHNS 
Figure 7: Log Per Capita Household Income by Age

Panel A: Urban

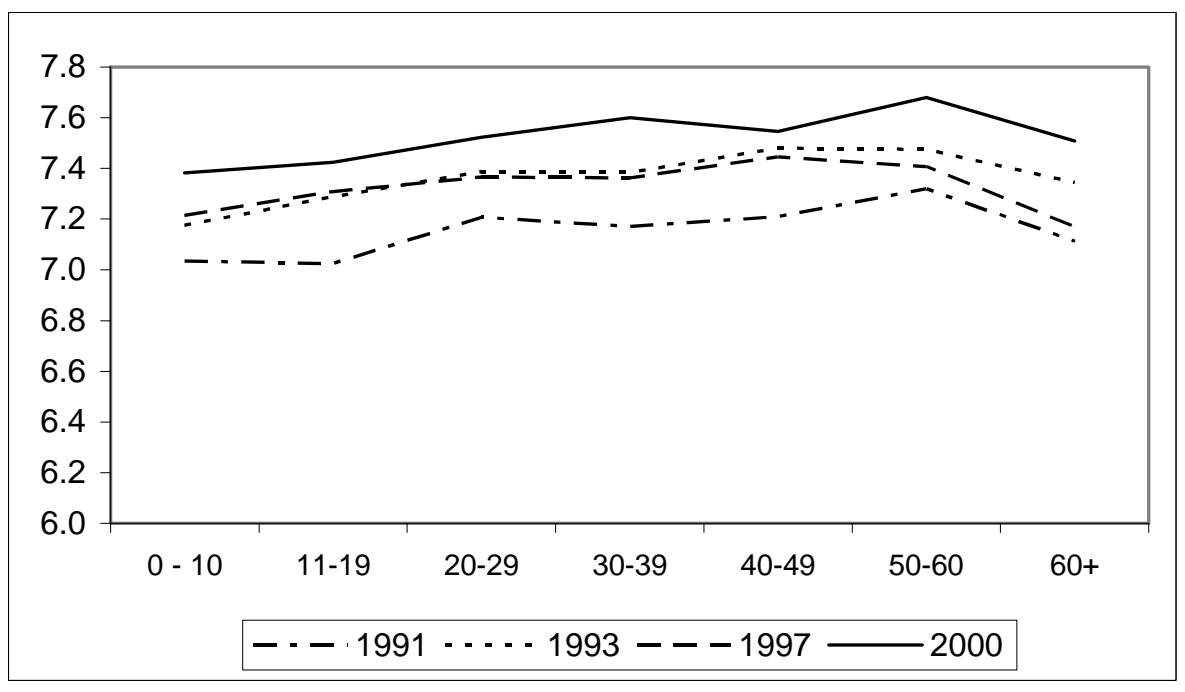

Panel B: Rural

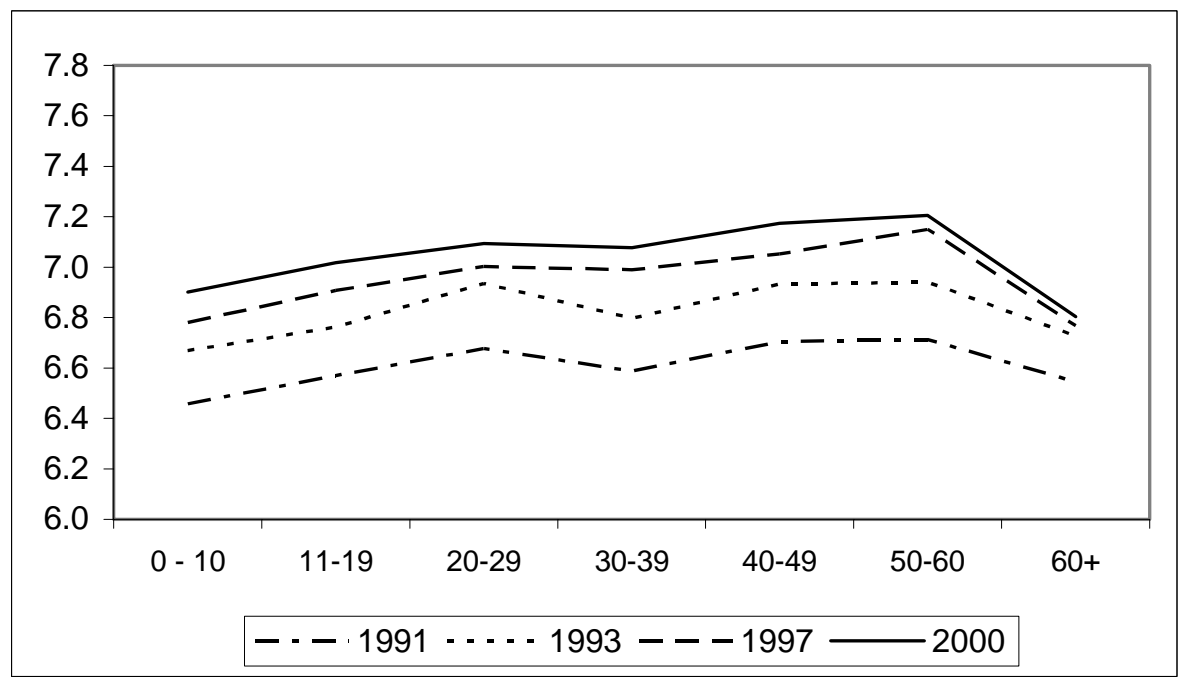

Source: Authors calculations based on the CHNS 